ESPECIFICIDADE HOSPEDEIRA E ASPECTOS BIOLÓGICOS DE Phaedon pertinax Stal, 1860 (COLEOPTERA, CHRYSOMELIDAE), PARA O CONTROLE BIOLÓGICO DE Bidens pilosa L. (ASTERACEAE)

FRANCO LUCCHINI

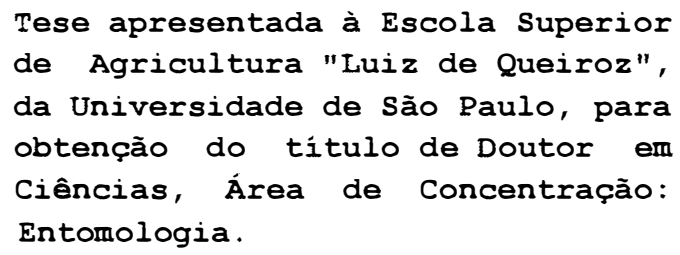

PIRACICABA

Estado de São Paulo - Brasil

Setembro - 1996 
Dados Internacionais de Catalogação na Publicação (CIP)

DIVISĀO DE BIBLIOTECA E DOCUMENTAÇÃO - Campus "Luiz de Queiroz"/USP

Lucchini, Franco

Especificidade hospedeira e aspectos biológicos de Phaedon perinax Stal, 1860 (COLEOPTERA, CHRYSOMELIDAE), para o controle biológico de Bidens pilosa L. (ASTERACEAE) / Franco Lucchini. - - Piracicaba, 1996.

75p. : il.

Tese (doutorado) - - Escola Superior de Agricultura Luiz de Queiroz, 1996.

Bibliografia.

1. Controle biológico 2. Inseto para controle biológico 3. Inseto fitófago 4. Planta daninha - Controle biológico l. Título

$$
\begin{array}{ll}
\text { CDD } & 595.7 \\
632.7 \\
632.96
\end{array}
$$


ESPECIFICIDADE HOSPEDEIRA E ASPECTOS BIOLÓGICOS DE Phaedon pertinax Stal, 1860 (COLEOPTERA, CHRYSOMELIDAE), PARA O CONTROLE BIOLÓGICO DE Bidens pilosa L. (ASTERACEAE)

\section{FRANCO LUCCHINI}

Engenheiro Agrônomo

Orientador: Prof. Dr. EVONEO BERTI FILHO

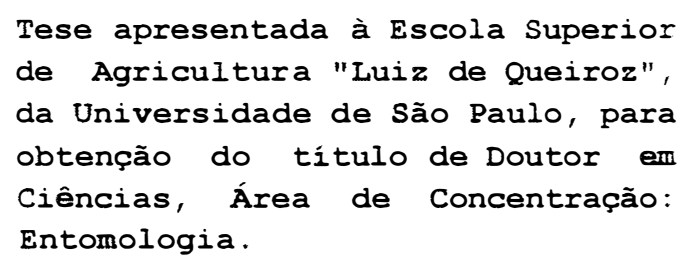

PIRACICABA

Estado de São Paulo - Brasil

Setembro - 1996 
ESPECIFICIDADE HOSPEDEIRA E ASPECTOS BIOLÓGICOS DE Phaedon pertinax Stal, 1860 (COLEOPTERA, CHRYSOMELIDAE), PARA O CONTROLE BIOLÓGICO DE Bidens pilosa L. (ASTERACEAE)

Franco Lucchini

Aprovada em: 08/11/1996

Comissão Julgadora:

Prof.Dr. Evoneo Berti Filho Prof.Dr. José Djair Vendramin

ESALQ/USP ESALQ/USP Prof.Dr. Gilberto José de Morais Dr. Condorcet Aranha ESALQ/USP IAC Prof.Dr. Zundir José Buzzi

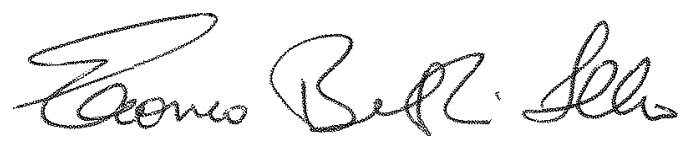

Prof.Dr. Evoneo Berti Filho Orientad or 
À Maria Lúcia, amiga e companheira nas horas difíceis;

Aos meus filhos: Daniel, Marcella e Steffano

DE D I C O 
Ao Dr. Evoneo Berti Filho, Professor do Departamento de Entomologia da ESALQ/USP, Piracicaba,SP, pelas críticas, revisãodos originais, confiança e apoio na elaboração da Tese.

Aos professores do curso de Pós-Graduação do Departamento de Entomologia da ESALQ/USP, pelos ensinamentos, compreensão e apoio na minha formação ac a dêmi ca.

À Empresa Brasileira de Pesquisa Agropecuária (EMBRAPA)/Centro Nacional de Monitoramento e Avaliação de Impacto Ambiental (CNPMA), pela oportunidade de execução desta pesquisa, facilidades e bolsa concedida.

A Escola Superior de Agricultura "Luiz de Queiroz"(ESALQ)/USP, pela oportunidade de realização do Curso de Doutorado.

À Dra. Maria Lúcia Saito, pesquisadora da EMBRAPA/CNPMA, pelos constantes incentivos, sugestões e ajuda na obtenção de algumas plantas.

Ao Dr. Condorcet Aranha, pesquisador do Instituto Agronômico de Campinas (IAC)/Seção de Botânica, pelo apoio, sugestões e identificação da maior parte das plantas da família Asteraceae.

Ao Prof. Dr. Zundir José Buzzi, da Universidade Federal do Paraná (UFPr)/Setor de Ciências Biológicas, pela identificação de Phaedon pertinax Stal.

Ao Dr. Arnildo Pott, pesquisador da EMBRAPA, Centro de Pesquisa Agropecuária do Pantanal (CPAP), Corumbá, MS, pela coleta e envio de sementes de Bidens gardneri Bak.

Aos Drs. J.E. Eger e Fred D. Bennett, da Universidade da Flórida, Departamento de Entomologia e Nematologia, Gainesville, USA, pela identificação do predador Stiretrus erythrocephalus (Lepel.\& Serv.).

À bibliotecária da EMBRAPA/CNPMA, Maria Amélia Toledo Leme, pela revisão das referências bibliográficas.

Aos colegas e funcionários do Departamento de Entomologia da ESALQ/USP e do Laboratório de Quarentena "Costa Lima" da EMBRAPA/CNPMA, que de alguma forma contribuíram na condução deste trabalho. 


\section{SUMÁRIO}

$\begin{array}{lr}\text { RESUMO } & \text { Página } \\ \text { SUMMARY } & \text { vi } \\ \text { SUiii }\end{array}$

1. INTRODUÇÃ O

2. REVISÃO DE LITERATURA

2.1. Controle biológico de plantas daninhas por insetos

2.2. Aspectos gerais sobre o gênero Phaedon Latreille

3. MATERIAL E MÉTODOS

3.1. Criação estoque de P. pertinax

14

3.2. Especificidade hospedeira

16

3.2.1. Larvas

18

3.2.2. Adultos

23

3.2.2.1. Alimentação

23

3.2.2.2. Postura

23

3.3. Aspectos biológicos de P. pertinax

26

3.3.1. Estágios imaturos

26

3.3.2. Estágio adulto

28

3.3.3. Tabela de vida de fertilidade 
4. RESULTADOS E DISCUSSÃO

4.1. Especificidade hospedeira

4.1. 1. Alimentação de larvas e adultos 32

4.1. 2. Postura e danos 38

4.2. Aspectos biológicos de P. pertinax 42

4.2.1. Ovo 42

4.2.1.1. Período de incubação e viabilidade 42

4.2.2. Larva 43

4.2.2.1. Determinação do número
de ínstares

4.2.2.2. Duração e viabilidade larval 44

4.2.2.3. Alimentação e danos 46

4.2.3. Pré-pupa e pupa 47

4.2.3.1. Duração e viabilidade 48

4.2.4. Adulto 49

4.2.4.1. Pré-postura, postura, póspostura, longevidade e razão sexual 52

4.2.4.2. Fecundidade e viabilidade do ovos 52

4.2.4.3. Alimentação e reprodução 53

4.2.5. Tabela de vida de fertilidade 55

4.3. Inimigos naturais $\quad 57$

4.4. Avaliação como agente de controle biológico 58

5. CONCLUSÕES 61

REFERÊNCIAS BIBLIOGRÁFICAS 63 
ESPECIFICIDADE HOSPEDEIRA E ASPECTOS BIOLÓGICOS DE Phaedon pertinax Stal, 1860 (COLEOPTERA, CHRYSOMELIDAE), PARA O CONTROLE BIOLÓGICO DE Bidens pilosa L. (ASTERACEAE)

Autor: Franco Lucchini

Orientador: Prof. Dr. Evoneo Berti Filho

\section{RESUMO}

A planta invasora Bidens pilosa L. é considerada naturalizada em diversos países, promovendo vários tipos de problemas, tais como: quedas de produção em culturas, efeitos alelopáticos em outras plantas e hospedeira de certas pragas e doenças. Com o intuito de avaliar a especificidade hospedeira do inseto Phaedon pertinax Stal, adaptado à $B$. pilosa, e o seu potencial como agente controle biológico desta espécie vegetal, estudaram-se 67 plantas, através de testes de não-preferência para alimentação e oviposição, e foram determinados alguns parâmetros de sua biologia, em condições de laboratório e campo, em Jaguariúna, Estado de São Paulo, procurando-se 
realizar uma avaliação de sua capacidade inata de dano e adequação de uso como agente de controle biológico. Os testes sem chance de escolha para larvas e adultos indicaram que o inseto se desenvolve de maneira satisfatória somente em Bidens spp. e Coreopsis sp., não provocando danos importantes às demais plantas. P. pertinax mostrou ser um inseto oligófago, desenvolvendo-se adequadamente em Bidens spp., restrito a poucas espécies da tribo Heliantheae, apresentando pela sua especificidade hospedeira e informações biológicas obtidas potencial como agente de controle biológico de $B$. pilosa, havendo algum risco para Coreopsis sp., em locais onde esta planta for considerada como ornamental. 
HOST SPECIFICITY AND BIOLOGICAL ASPECTS OF Phaedon pertinax Stal, 1860 (COLEOPTERA, CHRYSOMELIDAE) FOR THE BIOLOGICAL CONTROL OF THE WEED Bidens pilosa L. (ASTERACEAE)

Author: Franco Lucchini

Adviser: Dr. Evoneo Berti Filho

SUM M A R Y

Bidens pilosa L. is considered an introduced weed in many countries, where it promotes several types of problems, such as decline of crop yeild production, allelopathic effects in other plants, hostage for pests and plant diseases. This research deals with evaluation of the insect Phaedon pertinax Stal as a candidate for the biological control of $B$. pilosa. The experiments were set in Jaguariúna, State of São Paulo, Brazil. A total of 67 species of plants were submitted to the insect through tests of non-preference for feeding and oviposition. Some biological parameters of the insect were determined under laboratory and field conditions to evaluate the innate capacity of damage and the suitability of using as 
the innate capacity of damage and the suitability of using as an agent of biological control. Tests without choice chance for larvae and adults have indicated that the insect has good development only on Bidens spp. and Coreopsis sp. and did not cause important damages to the other plant species. P. pertinax is an oligophagous insect on Bidens spp. restricted to few species of the tribe Heliantheae. Therefore this insect presents a high potential as an agent of biological control of B. pilosa with some risk to Coreopsis sp. where this plant is considered as an ornamental one. 


\section{INTRODUÇÃ O}

As plantas daninhas são o maior problema mundial em termos de pragas agrícolas, quando se consideram as perdas de produção e os custos envolvidos no controle. Sua importância aumenta ao se incluírem os custos com estas em pastagens, florestas e ecossistemas aquáticos. Os herbicidas são utilizados em maior quantidade que qualquer outra classe de agrotóxico e o controle das plantas daninhas, de modo geral, é mais dispendioso que o de insetos, ácaros, nematóides ou doenças (CHARUDATTAN, 1993).

Entre as plantas invasoras de culturas, freqüentes no Brasil, destaca-se Bidens pilosa L. (Asteraceae), provavelmente originária da América Tropical (TAMASHIRO \& LEITÃO FILHO, 1978), e que atualmente tem distribuição cosmopolita, ocorrendo preferencialmente em solos argilosos e férteis, onde constitui sério problema (ARANHA et alii, 1982). É uma das mais sérias infestantes de culturas, considerada planta daninha em mais de 40 países (LORENZI,1982). Apresenta ampla dispersão nas regiões tropicais e subtropicais, com centro de origem no México (BALLARD, 1986). 
Reúne características morfológicas e biológicas de uma planta daninha típica: alta produção de sementes por planta, com elevada viabilidade, rápido desenvolvimento vegetativo, eficiente mecanismo de dispersão, ocorrência de várias gerações durante o ano, porte herbáceo e tolerância a vários ambientes, (Clements ${ }^{\prime}$ e Kirszenzaft ${ }^{2}$, citados por TAMASHIRO \& LEIT ÃO FILHO, 1978). MARINIS (1973), determinou ser alta a capacidade reprodutiva de $B$. pilos $a$ mesmo em condições de solo de baixa fertilidade.

No "Catálogo das espécies de mato infestantes de áreas cultivadas no Brasil - família do picão-preto (Compositae)", BLANCO (1976), relacionou 125 espécies consideradas problema, ou que apresentam ameaça potencial à agricultura e pecuária considerando sete espécies como altamente nocivas: Acanthospermum australe, A. hispidum, Baccharis coridifolia, Bidens pilosa, Eclipta alba, Galinsoga parviflora e Vernonia polyanthes. No Brasil B. pilosa encontra-se freqüentemente associada às culturas de algodão, batata, café, cana-de-açúcar, cebola, chá, citros, feijão, hortaliças, mandioca, milho, morango, soja e pomares diversos, em qualquer tipo de solo. Realizando um inventário florístico da comunidade de

1 CLEMENTS. F.E. Plant sucession and indicator. New york. Hafner. 1928.453 p.

2 KIRSZENZAFT. S.L. Desenvolvimento vegetativo de Bidens pilosa L. Tese. Escola Paulista de Medicina. São Paulo. 1975. $134 \mathrm{p}$. 
plantas daninhas que infestam campos de milho, BLANCO \& SANTOS (1988) mencionaram que o picão-preto estava presente em $27,5 \%$ das áreas.

Uma comunidade de plantas daninhas, com predomínio de B. pilosa provocou quedas na produção de café, que variaram de 55,9 a 77,2\% (BLANCO et alii, 1982). Na cultura do feijão CERNA \& VALDÉZ (1987) encontraram uma redução de 18,75\%, devido a competição com esta espécie.

O picão-preto é facilmente controlável por diversos herbicidas, no entanto a grande abundância desta espécie associada à facilidade de novas infestações tornam, muitas vezes, o controle químico inviável (TAMASHIRO \& LEITÃO FILHO, 1978).

Efeitos alelopáticos de exsudatos da raiz de $B$. pilosa sobre Lactuca sativa L., Phaseolus vulgaris L., Zea mays L. e Sorghum bicolor (L.) foram estudados por STEVENS \& TANG (1985), demonstrando que o picão-preto inibe significativamente o crescimento de todas as espécies das culturas testadas.

Esta planta pode ser hospedeira de diversas pragas e doenças de plantas cultivadas abrigando insetos, nematóides, vírus e fungos (KISSMANN \& GROTH, 1992).

Tendo em vista a importância de B. pilosa como planta invasora e por ser uma planta exótica (naturalizada), pode-se propor um programa de controle biológico clássico para esta espécie. 
Programas de controle biológico clássico de plantas daninhas devem consistir de estudos de pré-introdução abrangendo sua distribuição e ecologia, descoberta de inimigos naturais adaptados à planta alvo, estimativas sobre sua eficácia, seleção dos melhores candidatos, exame de sua segurança como agentes de controle biológico e estudos de pós-introdução para determinar seu estabelecimento e efeito sobre a população da planta daninha (WAPSHERE, 1975). No entanto, em toda pesquisa conduzida por este sistema é necessário assegurar-se de que os inimigos naturais presentes, nativos e adaptados ou eventualmente introduzidos, sejam efetivos e específicos.

O objetivo deste trabalho foi avaliar o grau de especificidade de $P$. pertinax e estudar sua biologia. Determinou-se sua provável faixa de hospedeiros, através de testes de não-preferência para alimentação e oviposição em plantas da família de B. pilosa (Asteraceae) e em outras plantas de interesse econômico ou social, e foram determinados alguns parâmetros de sua biologia, em condições de laboratório e campo. 


\section{REVISÃO DE LITERATURA}

\subsection{Controle biológico de plantas daninhas por insetos}

A importância em selecionar agentes de controle biológico de plantas daninhas, que com segurança não passem a atacar plantas de interesse econômico, deve ser demonstrada pela sua eficácia em controlar a planta alvo. As etapas metodológicas a serem seguidas baseiam-se, principalmente, nas propostas de HARRIS \& ZWOLFER (1968), HARRIS (1973), GOEDEN (1983) e SCHROEDER \& GOEDEN (1986). HUFFAKER (1957 e 1959), WILSON (1964) e WAPSHERE et alii (1989) prepararam revisões sobre o controle biológico de plantas daninhas. ZWOLFER \& HARRIS (1971) revisaram a determinação da especificidade hospedeira de insetos.

Uma análise das tentativas de controle biológico de plantas daninhas anteriores a 1980 foi realizada por JULIEN et alii (1984); as informações coletadas de 174 projetos para o controle de 101 espécies mostraram que 39\% dos projetos foram considerados bem sucedidos e elevaram o nível de controle de 38 plantas. Os insetos compreenderam $98 \%$ das liberações e mais de 94\% foram de Coleoptera, Lepidoptera, Hemiptera e Diptera. 
$\mathrm{O}$ uso de agentes nativos resultou em $62 \%$ de controle efetivo (11 espécies de insetos), no entanto, ecologicamente, podem ser considerados "exóticos" pois muitas liberações foram realizadas onde as espécies não habitavam anteriormente.

Os métodos tradicionalmente utilizados para a seleção de insetos fitófagos, no controle biológico clássico de plantas daninhas, consistiam basicamente das técnicas aplicadas por teste de fome ou do teste negativo de oviposição sobre plantas de importância econômica. Estes, entretanto, não garantiam a potencialidade do inseto como agente de controle, visto que insetos aprisionados em laboratório comumente podem por ovos ou se alimentar sobre um número maior de plantas do que normalmente o fazem na natureza. Observando estes aspectos, HARRIS \& ZWOLFER (1968) demostraram a necessidade de se utilizar outras técnicas, propondo os seguintes estudos : 1) biologia, incluindo adaptações ao restrito grupo de hospedeiros; 2) revisão das plantas atacadas pelos insetos relacionados; 3 ) determinação em laboratório da faixa de hospedeiros do inseto; 4) investigações sobre as bases químicas e físicas de reconhecimento inseto-planta; 5) testes de fome sobre plantas de interesse econômico e 6) estabelecimento do potencial efetivo para o controle da planta daninha. 
HARRIS (1973), com base na discussão de vários métodos, verificou que era dada pouca atenção à seleção de agentes efetivos para o controle biológico de plantas daninhas, propondo um sistema de pontuação por valores para a incorporação das melhores características. Este passou a ser utilizado como um modelo para predizer a eficácia de insetos fitófagos a serem introduzidos.

No entanto, GOEDEN (1983) elaborou uma revisão crítica do sistema de Harris, propondo modificações que o melhoraram, considerando os seguintes parâmetros: I) Avaliação inicial da capacidade inata de dano - 1. dano direto em condições de campo, 2. danos indiretos, 3. fenologia do ataque, 4. número de gerações, 5. número de progênie por fêmea por geração e 6. fatores extrínsecos de mortalidade; II) Adequação de uso como agente de controle biológico - 1. fonte da planta hospedeira do inseto, 2. facilidade de criação, 3 . segurança potencial e 4. especificidade hospedeira; e III) Eficácia potencial na área de introdução - 1. evidência de eficácia como agente de controle biológico, 2. similaridade ecoclimática e 3 . história da colonização do agente (APÊNDICE 1). De acordo com uma aplicação deste modelo revisado, um candidato não deve ter menos de 20 pontos, pois provavelmente não será efetivo como agente de controle biológico, valores entre 20 e 50 mostram eficácia parcial, e devem ser complementados por importação de outros agentes, e acima de 50 podem mostrar sucesso na introdução. 
O sistema proposto por HARRIS (1973) e revisado por GOEDEN (1983), tem se revelado atualmente um modelo básico difundido entre pesquisadores em controle biológico de plantas daninhas e passou a permitir melhor avaliação da especificidade hospedeira, através da determinação da eficácia potencial aplicada por este método de pontuação. Entre outras informações, para a aplicação deste sistema, é de fundamental importância conhecer a faixa de hospedeiros do inseto e sua biologia.

WAPSHERE (1975) salientou ser essencial que o agente de controle biológico não ataque nenhuma cultura ou planta de importância social (não comercializada normalmente), e por essa razão é imperativo demonstrar que este limitará sua ação sobre a planta alvo e espécies próximas. Este autor sugeriu então uma estratégia para avaliar a segurança de organismos para controle biológico de plantas daninhas, que consiste na seleção filogenética, através de uma seqüencia de testes, considerando outras formas da espécie da planta alvo, espécies do mesmo gênero, membros da mesma tribo, sub-família, família e ordem.

Durante um programa de seleção, todas as plantas escolhidas são expostas a agente potencial de controle, em uma série de testes, realizados de acordo com as características de cada espécie de inseto. Estes ensaios determinam se o agente aceita ou não a planta teste como alimento ou para oviposição; os insetos são deixados em jejum, para que resultados negativos sejam obtidos durante os testes de 
alimentação e oviposição (testes de fome); o inseto comportandose como monófago ou oligófago pode ser considerado seguro para uma introdução. Os ensaios de laboratório são suficientes para determinar a segurança do agente potencial; entretanto, quando há dúvidas, ensaios de campo no local de origem podem ser realizados (INTERNATIONAL INSTITUTE OF BIOLOGICAL CONTROL, 1986).

\subsection{Aspectos gerais sobre o gênero Phaedon Latreille}

Muitas das aproximadamente oitenta espécies de Phaedon (Col., Chrysomelidae, Chrysomelinae, Phaedonini) descritas são aparentemente oligófagas e se alimentam de um número restrito de hospedeiros, em uma ou várias famílias de plantas relacionadas. Poucas são consideradas ocasionalmente pragas de culturas, como: Phaedon cochleariae (F.), que ocorre na Europa, África do Norte e Oriente Médio, alimentando-se exclusivamente de Crucíferas (Brassica spp., Raphanus spp., Rorippa nasturtium-aquaticum (L.) Hayek) e Phaedon armoraciae (L.), espécie assinalada na América do Norte e Europa, alimentando-se de plantas aquáticas, sendo a de importância econômica $R$. nasturtium-aquaticum (agrião). Certas espécies de Phaedon podem demonstrar valor como agentes de controle biológico de várias espécies de plantas daninhas, como por exemplo Rubus spp. (Rosaceae) e Flaveria bidentis (L.)(Asteraceae) (COX, 1991). 
Phaedon consimile Stal foi uma espécie estudada na Argentina para o controle biológico de $F$. bidentis (MORÁN LEMIR, 1983 e 1985). P. pertinax, entre outras espécies que se desenvolvem em $B$. pilosa, está sendo objeto de investigação para o controle dessa planta daninha no sudeste da Ásia (WATERHOUSE, D. - 1993, CSIRO, informação pessoal).

Na América do Sul e Central são raras as informações sobre o gênero Phaedon. BECHYNÉ (1950) e LIMA (1953) elaboraram chaves taxonômicas para a separação das espécies sul-americanas. Phaedon semimarginatus Latr. apresenta várias sub-espécies e ocorre na Colômbia, Equador, México, Chile, Peru e Argentina; Phaedon affine Guérin, no Brasil, Paraguai, Argentina e Bolívia; Phaedon confine Klug, no Brasil, Paraguai e Argentina; Phaedon bonariense Bohem., na Argentina e Bolívia; P. pertinax, no Brasil e Peru; P. consimile, no Brasil, Paraguai, Bolívia e Equador; Phaedon fuscipes Stal, na Venezuela, Colômbia e Bolívia; e Phaedon stilpnus Stal, no Peru e Bolívia. A separação de $P$. pertinax de $P$. consimile é dificultada pela semelhança entre as duas espécies, a segunda é menor que a primeira e apresenta diferenças quanto a reticulação microscópica dos élitros (BECHYNÉ, 1950). No entanto, LIMA (1953) considerou $P$. consimile como sinonímia de $P$. pertinax, argumentando que os caracteres diferenciais não têm valor específico, a descrição de $P$. consimile corresponde ao que se vê nos machos de $P$. pertinax, os quais são menores que as fêmeas. 
LIMA (1936, 1953 e 1955) e RIBEIRO (1953) relataram que larvas e adultos de $P$. pertinax alimentam-se de $B$. pilosa. MENDES (1938a) apresentou uma relação dos insetos encontrados sobre plantas do Estado de São Paulo nos anos de 1937-1938, onde também relatou esta espécie sobre a mesma planta. MENDES (1938b) afirmou que $P$. pertinax é muito freqüentemente encontrado atacando folhas de algodoeiro, nos primeiros meses do ano. Segundo SILVA et alii (1968), a larva desta espécie cria-se em picão-preto e o adulto alimenta-se de folhas de algodoeiro, maria-mole e videira, distribuindo-se nos Estados de Pernambuco, Minas Gerais, Rio de Janeiro, São Paulo e Rio Grande do Sul.

Bosq ${ }^{1}$, citado por MORÁN LEMIR (1983), relatou para a Argentina a espécie Phaedon affine Guérin sobre Baccharis serrulata (sin. pingraea) DC (Compositae).

BERTELS (1953) mencionou que $P$. confine encontrase às vezes em batata inglesa, embora prefira Senecio brasiliensis Less. como planta hospedeira. Estudando a biocenose de solanáceas cultivadas e selvagens, BERTELS (1962) relatou $P$. confine somente em batata. De acordo com SILVA et alii (1968), o adulto desta espécie alimenta-se de folhas

1 BosQ, J.M. Segunda lista de Coléopteros da la República Argentina, dañinos a la agricultura. Min. Agric. Nac.. Dir. San. Veg., Div. Zool. Agric.. 80 pp.. 1942 . 
de batatinha, maria-mole e milho, distribuindo-se nos Estados do Paraná, de São Paulo e do Rio Grande do Sul.

Para P. consimile, MORÁN LEMIR (1983), estudou sua biologia e o efeito de seu ataque sobre $F$. bidentis; as larvas e os adultos se alimentam da parte aérea da planta. Este autor observou ainda em pequena escala danos a plantas dos gêneros Bidens e Tagetes, mostrando preferência por Flaveria, pois quando esta termina seu ciclo o inseto não recorre às outras plantas mencionadas. Determinando a entomofauna relacionada com $F$. bidentis, MORÁN LEMIR (1985) considerou que $P$. consimile é a principal espécie causadora de danos apreciáveis a esta planta.

Sobre $P$. pertinax poucos aspectos são relatados. RIBEIRO (1953) verificou que as larvas são de coloração preta com o corpo coberto de pilosidade e tubérculos, e ao serem tocadas liberam um fluido viscoso de defesa. Quando completam seu desenvolvimento atinge $7,0 \mathrm{~mm}$ de comprimento e penetram no solo, a $1 \mathrm{~cm}$ de profundidade, formando uma câmara pupal; a pupa é de cor amarela e após 6 a 8 dias emerge o adulto. Ao emergirem, são de coloração quase negra, com o pronoto avermelhado, e posteriormente adquirem tom metálico que varia do verde ao azul; o inseto não é um bom voador podendo ser facilmente coletado com as mãos (sic). 
Quanto a inimigos naturais do gênero Phaedon, RIBEIRO (1953) citou Stiretrus erythrocephalus (Lepel. \& Serv., 1825) (Hemiptera-Heteroptera, Pentatomidae), que mostra grande semelhança (mimetismo) com a presa, apresentando a mesma cor geral do corpo do adulto de P. pertinax; preda larvas e adultos. MORÁN LEMIR (1983) assinalou, na Argentina, a predação de ovos, larvas e adultos de $P$. consimile por ninfas e adultos de $S$. erythrocephalus; Stiretrus sp.(circundatus) e Podisus chilensis Spinola (Hemiptera-Heteroptera, Pentatomidae) também foram encontrados predando larvas e adultos; Hyalomydes brasiliensis Towsend (Diptera, Tachinidae) parasita adultos de P. consimile. 


\section{MATERIAL E MÉTODOS}

A pesquisa foi desenvolvida no Departamento de Entomologia, Escola Superior de Agricultura "Luiz de Queiroz" (ESALQ), da Universidade de São Paulo (USP), Campus de Piracicaba, SP, no Laboratório de Quarentena "Costa Lima" e Laboratório de Entomologia, ambos, do Centro Nacional de Pesquisa de Monitoramento e Avaliação de Impacto Ambiental (CNPMA), da Empresa Brasileira de Pesquisa Agropecuária (EMBRAPA), em Jaguariúna, SP.

\subsection{Criação estoque de $P$. pertinax}

Para a realização dos ensaios manteve-se em laboratório uma criação estoque de $P$. pertinax, iniciada com insetos provenientes de Mogi-das-Cruzes, SP, coletados no sítio de propriedade do Sr. Yukiteru Inoue, Rodovia Mogi-Bertioga, $\mathrm{km} 4$. 
A criação foi desenvolvida a $24 \pm \pm \quad 3 \quad{ }^{\circ} \mathrm{C}$ de temperatura, $70 \pm 10 \%$ de umidade relativa e com fotofase de 12 horas no outono-inverno, e de 14 horas na primavera-verão, onde também eram realizados os experimentos de especificidade hospedeira. Adultos de P. pertinax foram coletados de dezembro a janeiro em áreas de vegetação espontânea de $B$. pilosa ou em Culturas onde era infestante, estes insetos foram levados ao laboratório e colocados em potes plásticos com tampa, de capacidade de $200 \mathrm{ml}$, perfurados lateralmente. Em cada recipiente foram mantidos de 20-40 adultos não sexados, utilizando-se de 8 a 12 potes, correspondendo a $160-480$ insetos.

As folhas de $B$. pilosa fornecidas como alimento, provenientes de áreas infestadas do campo experimental do CNPMA, eram lavadas com água corrente e deixadas a secar, antes de se realizar a substituição de alimento, que era trocado em dias alternados. As posturas colhidas eram transferidas para potes plásticos transparentes de capacidade de $500 \mathrm{ml}$, onde os ovos permaneciam até a eclosão das larvas.

Nestes mesmos potes de $500 \mathrm{ml}$ criaram-se as larvas até o estágio de pré-pupa, utilizando-se o mesmo procedimento de alimentação dos adultos. Quando as larvas de último ínstar deixavam de se alimentar, eram transferidas para potes plásticos transparentes de capacidade de $250 \mathrm{ml}$, perfurados lateralmente, contendo no fundo, aproximadamente, $2 \mathrm{~cm}$ de solo arenoso autoclavado para a pupação. 
A substituição dos adultos em postura ocorreu a cada dois meses e a cada quatro gerações toda a criação era renovada, com material de campo, visando evitar degeneração da espécie.

\subsection{Especificidade hospedeira}

A metodologia utilizada para a determinação da possível faixa de hospedeiros de $P$. pertinax foi, em parte, a recomendada por WAPSHERE (1974 a e b, e 1975), que sugere para demonstração de segurança de introdução de insetos no controle biológico de plantas daninhas um sistema filogenético de seleção de plantas a serem testadas. As plantas da ordem Asterales, que é representada apenas pela família Asteraceae (Compositae), foram selecionadas de modo a conseguir-se pelo

menos uma representante de cada tribo, adotando-se a posição taxonômica utilizada por BARROSO et alii (1986), que consideram para as plantas, presentes no Brasil, a sub-família Lactucoideae: tribos Lactuceae, Mutisieae, Arctotideae, Carduceae, Vernonieae e Eupatorieae, e a sub-família Asteroideae: tribos Senecioneae, Tageteae, Heliantheae, Inuleae, Anthemideae, Calenduleae, Cotuleae e Astereae. Para a tribo Heliantheae, na $B$. pilosa está incluída, foram utilizadas o maior número possível de espécies. 
As plantas, da família Asteraceae, não comerciais, foram taxonomicamente identificadas pelo Dr. Condorcet Aranha do Instituto Agronômico, Campinas, SP, Seção de Botânica; as exsicatas estão registradas e depositadas no Herbário daquela Instituição.

Para a seleção das plantas comerciais, ou não, utilizadas nos experimentos, consideraram-se os trabalhos da literatura e referências de museus entomológicos; onde foi constatada a ocorrência de insetos do gênero Phaedon, ou culturas onde a presença de B. pilosa é freqüente.

A obtenção das plantas daninhas foi realizada através da coleta de mudas ou sementes em áreas infestadas, orientandose pelos trabalhos de LORENZI (1982), ARANHA et alii (1988) e KISSMANN \& GROTH (1992), as quais foram utilizadas nos testes diretamente ou transplantadas ou semeadas em vasos e mantidas em telado. Para as plantas comerciais ou ornamentais adquiriram-se mudas ou sementes das variedades mais freqüentemente comercializadas.

Foram realizados experimentos de não-preferência com larvas e adultos de $P$. pertinax para alimentação e de adultos para oviposição, com e sem chance de escolha, usando-se as espécies vegetais como tratamentos (TABELA 1), com o objetivo de determinar a possível faixa de hospedeiros desta espécie de inseto; a planta no 22, Bidens pilosa L., trata-se da forma típica e a planta $\mathrm{n}-23$, B. pilosa (=subalternans), trata-se de forma 
considerada por KISSMANN \& GROTH (1992) como $B$. subalternans DC.

Os resultados obtidos foram submetidos a análise de variância e as médias comparadas pelo teste de Tukey ao nível de $1 \%$ de probabilidade.

\subsubsection{Larvas}

Este experimento de não-preferência foi realizado com folhas das diferentes espécies (TABELA 1), expondo-as a larvas de primeiro ínstar $P$. pertinax, sem chance de escolha. As folhas foram lavadas e deixadas sobre papel, até perderam o excesso de umidade. A seguir eram cortadas de forma a apresentarem 8-10 $\mathrm{cm}^{2}$ de área; as folhas estreitas, foram justapostas, ou colocada uma quantidade suficiente para a alimentação das larvas. Posteriormente eram colocadas em caixas plásticas de $6,1 \mathrm{~cm}$ de diâmetro e $2,1 \mathrm{~cm}$ de altura. Ao lado das folhas foi posto uma pequena quantidade de papel umedecido, para a manutenção da umidade.

Após este procedimento, colocaram-se as larvas de $P$. pertinax, com 0-24 horas de idade, sobre as folhas com o auxílio de um pincel fino e distribuídas em 5 caixas plásticas, totalizando 100 larvas. As espécies vegetais eram testadas de acordo com a sua disponibilidade e em semanas diferentes para facilitar as observações. 
TABELA 1. Relação das plantas utilizadas nos testes de antixenose a Phaedon pertinax stal, 1860 (Col., Chrysomelidae).

№ Espécie Nome comum

\section{ASTERACEAE (COMPOSITAE)}

I. Sub-familia Lactucoideae

Tribo 1. Lactuceae (Cichorieae)

1 Cichorium endivia $I$.

2 Lactuca sativa I.

Escarola

3 Sonchus oleraceus I.

Tribo 2. Mutisieae

4 Chaptalia nutans (L.) Polak

Alface

Serralha

5 Gerbera sp.

Tribo 4. Arctotideae

6 Gazania sp.

Tribo 5. Carduceae (Cynareae)

7 Cynara scolymus L.

Tribo 6. Vernonieae

8 Vernonia polyanthes Less.

Tribo 8. Eupatorieae

9 Ageratum conyzoides L.

10 Mikania cordifolia (L.f.) Willd

11 Eupatorium pauciflorum H.B.R.

Lingua-de-vaca

Gerbera

Gazania

Alcachofra

Assa-peixe

Mentrasto

Cipó-cabeludo

Cambará

II. Sub-família Asteroideae

Tribo 9. Senecioneae

12 Emilia sonchifolia DC.

13 Senecio brasiliensis Less. (1 e 2)

Falsa-serralha

14 Senecio sp1.

Maria-mole

Tribo 10. Tageteae

16 Porophyllum ruderale (Jacq.)

Cinerária

Cinerária

Tagetes erecta L. (3)

Couve-cravinho

17 Tagetes erect

18 Tagetes sp.

Tribo 11. Heliantheae

19 Xanthium cavanillesii Schouw.

20 Ambrosia polystachya DC.

21 Bidens gardneri Bak.

22 Bidens pilosa L. (1 e 3)

23 Bidens pilosa L. (=B.subaltemans DC)

24 Bidens rubifolia H.B.K.

Tagetes

Tagetes

Carrapichão

Artemísia

Picão-do-pantanal

Picão-preto

Picão-preto

(continua) 
TABELA I. (continuação)

Nㅇ Espécie Nome comum

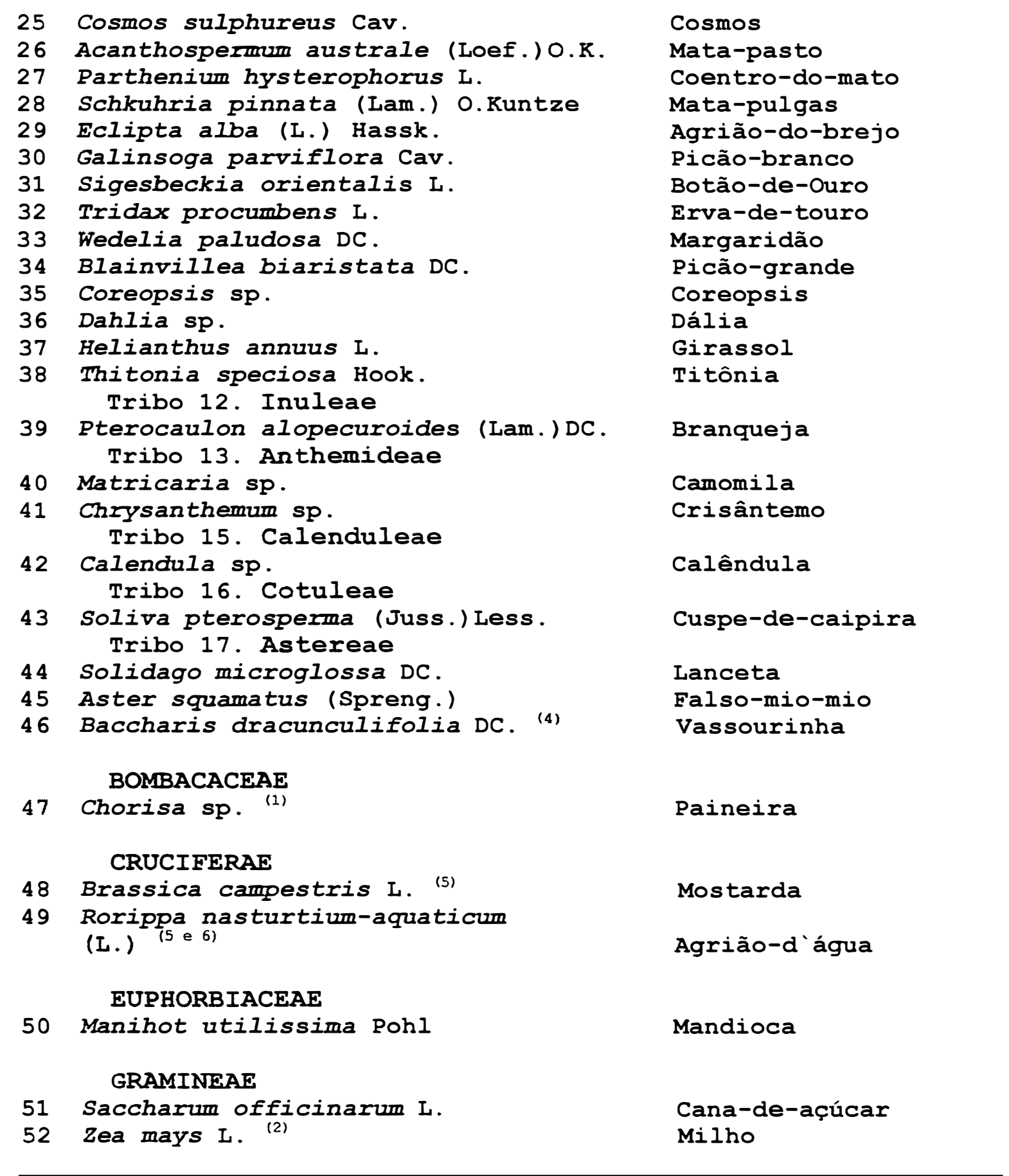

(continua) 
TABELA 1. (continuação)

\begin{tabular}{|c|c|c|}
\hline $\mathrm{N} \circ$ & Espécie & Nome comum \\
\hline \multicolumn{3}{|c|}{ JUGLANDACEAE } \\
\hline 53 & Carya ellinoensis C.Kock (1) & Nogueira pecan \\
\hline \multicolumn{3}{|c|}{ LEGUMINOSAE } \\
\hline 54 & Glycine $\max$ (L.)Merril (1) & Soja \\
\hline \multirow[t]{2}{*}{55} & Phaseolus vulgaris $\mathrm{L}$. & Feijão \\
\hline & LILIACEAE & \\
\hline \multirow[t]{2}{*}{56} & Allium cepa L. & Cebola \\
\hline & MALVACEAE & \\
\hline \multirow[t]{2}{*}{57} & Gossypium hirsutum L. (1) & Algodoeiro \\
\hline & $\begin{array}{l}\text { MORACEAE } \\
\text { Ficus carica L. }\end{array}$ & Figueira \\
\hline 58 & PEDALIACEAE & \\
\hline \multirow[t]{2}{*}{59} & Sesamum indicum L. & Gergelim \\
\hline & ROSACEAE & \\
\hline 60 & Fragaria sp. & Morango \\
\hline \multirow[t]{2}{*}{61} & Prunus persica (L.)Batsh. & Pessegueiro \\
\hline & $\begin{array}{c}\text { RUBIACEAE } \\
\text { Coffea arabica L. }\end{array}$ & Café \\
\hline 62 & RUTACEAE & \\
\hline \multirow[t]{2}{*}{63} & Citrus sp. & Laranjeira \\
\hline & SOIANACEAE & \\
\hline 64 & Nicotiana tabacum L. (1) & Fumo \\
\hline \multirow[t]{2}{*}{65} & Solanum tuberosum L. (2) & Batata-inglesa \\
\hline & THEACEAE & \\
\hline 66 & Thea sinensis L. & Chá \\
\hline & VITACEAE & \\
\hline 67 & Vitis vinifera L. (1) & Videira \\
\hline
\end{tabular}

(1) Gêneros ou espécies de plantas en que se assinalou
P. pertinax,
(2) P. confine,
(3) P. consimile,
(4) P. affine,
(5) P. cochleariae e
(6) P. armoraciae. 
As avaliações foram realizadas a cada 48 horas, contando-se o número de larvas sobreviventes e do dano visual, estabelecido por uma escala de níveis (TABELA 2). Nesta ocasião trocavam-se as folhas.

As larvas que conseguiam atingir a fase de pré-pupa, eram transferidas para copos plásticos de $250 \mathrm{ml}$, com tampa e perfurados lateralmente na parte superior, que continham de 2-3 $\mathrm{cm}$ de solo arenoso autoclavado e umedecido, e deixadas completar a fase de pupa; os adultos obtidos foram submetidos a alimentação na mesma planta teste em que se criaram, verificando-se a sua sobrevivência.

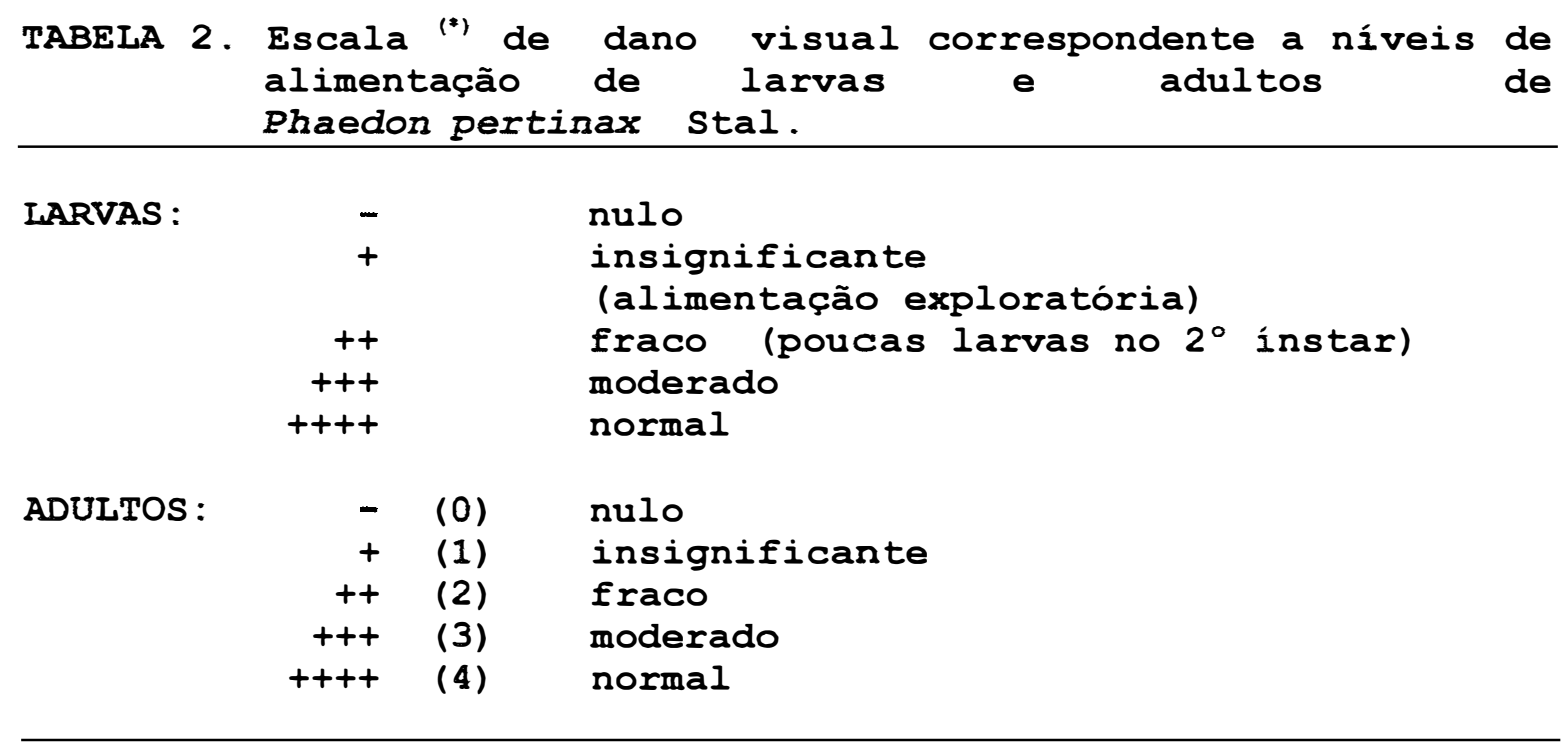

(*) Baseada nos trabalhos de:

Huber \& Vayssieres (1990)

Adair \& Scott (1991)

Eorno et alii (1992) 


\subsubsection{Adultos}

\subsubsection{Alimentação}

Este ensaio foi realizado visando verificar a nãopreferência de adultos por folhas de plantas invasoras, comerciais e ornamentais (TABELA 1), sem chance de escolha.

As folhas das espécies foram preparadas do mesmo modo que no experimento anterior. Pedaços destas folhas eram colocados em copos plásticos de $50 \mathrm{ml}$ com tampa de acrílico transparente, contendo sob esta, um pequeno pedaço de papel umedecido. Para cada planta foram utilizados 20 adultos de $P$. pertinax, com 24-48 horas de idade, que eram transferidos para os copos com auxílio de pincel macio. Em cada copo foram colocados 5 adultos.

A avaliação foi feita em dias alternados, pela contagem de adultos vivos e mortos, e do dano visual às plantas de acordo com a escala de pontos (TABELA 2), durante vinte dias.

\subsubsection{Postura}

Neste experimento estudou-se a não-preferência para oviposição sobre folhas de plantas invasoras, comerciais e ornamentais. 
Para a obtenção de fêmeas em oviposição foram utilizados de 24-36 casais com 8-15 dias de idade da criação estoque de $P$. pertinax, que eram transferidos para copos plásticos de $50 \mathrm{ml}$, com tampa acrílica. Estes casais, quando a fêmea estava em postura, eram utilizados nos testes, os quais foram renovados a cada 1-2 meses.

a) com chance de escolha.

Para este teste utilizaram-se placas de Petri com 150 $\mathrm{mm}$ ou $200 \mathrm{~mm}$ de diâmetro, como arenas, onde foi realizada a série de testes, com uma a seis plantas de cada vez, de acordo com a disponibilidade de material. Quando houve resposta positiva de alimentação nos experimentos com larvas e adultos, as plantas foram avaliadas separadamente.

As folhas, preparadas da mesma maneira que nos ensaios anteriores, eram cortadas com tesoura de modo a se obter de 6-8 $\mathrm{cm}^{2}$ de área; dependendo do tipo de folha foi colocada uma quantidade suficiente para alimentação e oviposição. Os pedaços de folhas das diferentes plantas (TABELA 1) eram dispostos de maneira aleatória eqüidistantes entre si, ao fundo da arena, sobre papel umedecido. Para cada série de plantas foram empregados dez casais em postura, um por placa de Petri. 
As avaliações foram realizadas em dias alternados, ocasião em que se trocava as folhas, durante dez dias; os ovos presentes nas diferentes plantas eram contabilizados.

A cada bateria de testes a planta testemunha, $B$. pilosa, estava presente entre os tratamentos.

Para Bidens spp. e Coreopsis sp. foi realizado experimento à parte, visando observar o comportamento de postura e danos a estas plantas quando expostas simultaneamente a P. pertinax.

b) sem chance de escolha.

A metodologia empregada nesta experiência foi a mesma que no ensaio com chance de escolha. Neste caso, foram utilizados cinco casais em postura e não estava presente a planta B. pilosa. 


\subsection{Aspectos biológicos de P. pertinax}

Para o início desta pesquisa foram utilizados ovos provenientes de adultos de campo, coletados em Mogi-dasCruzes, SP, e ovos, larvas e adultos da criação estoque.

O estudo da biologia, incluindo alguns aspectos morfológicos e comportamentais, foi realizado em laboratório e campo. As condições de temperatura, umidade e fotoperíodo foram as naturais; durante o desenvolvimento do trabalho a temperatura e a umidade relativa eram registradas em termohigrógrafo, que apresentaram oscilações de $26 \pm 3{ }^{\circ} \mathrm{C}$ para temperatura máxima e de $22 \pm 3{ }^{\circ} \mathrm{C}$ para temperatura mínima, e umidade relativa de $81 \pm 3 \%$ para máxima e de $57 \pm 6 \%$ para mínima.

As medições e observações foram feitas através de um microscópio estereoscópico OLYMPUS UMT $1 \mathrm{X}$ e $4 \mathrm{X}$ com ocular graduada (10X), calibrada com régua WILD 310345.

\subsubsection{Estágios imaturos}

Os seguintes parâmetros foram observados: duração e viabilidade dos estágios de ovo, larva, pré-pupa e pupa. Número e duração dos ínstares larvais. 
As larvas recém-eclodidas, e quando atingiam o máximo desenvolvimento em cada ínstar, eram medidas e observado o seu aspecto.

Para a observação do período de incubação 174 ovos coletados de adultos provenientes do campo foram recortados de posturas em folhas de B. pilosa e dispostos em grupos de 13-23, em 10 caixas plásticas de $6,1 \mathrm{~cm}$ de diâmetro por $2,1 \mathrm{~cm}$ de altura.

Nos estudos da fase larval foram utilizadas 84 larvas recém-eclodidas. Estas eram distribuídas em grupos de 12, com o auxílio de um fino pincel, em caixas plásticas. A alimentação constituiu-se de folhas de B. pilosa, adotando-se o mesmo procedimento da criação estoque. As folhas eram coletadas e substituídas diariamente, cortando-as e dispondo-as nas caixas de modo que houvesse alimentação suficiente para as larvas. A duração dos ínstares e o número de ecdises foram determinados pelo registro da largura da cápsula cefálica, até o início da fase de pré-pupa, quando as larvas deixavam de se alimentar; a viabilidade foi determinada pela porcentagem de sobrevivência até esta fase.

Após o término da fase larval, as pré-pupas foram transferidas para potes de vidro $6,0 \mathrm{~cm}$ de diâmetro por $7,5 \mathrm{~cm}$ de altura, com tampas plásticas de $6,1 \mathrm{~cm}$ de diâmetro, contendo 
$2 \mathrm{~cm}$ de solo arenoso autoclavado, umedecido, onde ocorreu a pupação; foi registrado o número de adultos que emergiram.

A determinação do período de pré-pupa foi feita de maneira indireta. Para esta observação foram utilizadas 185 larvas em início desta fase, que eram coletadas da criação estoque e transferidas para 15 potes de vidro, com o mesmo procedimento anterior, cada pote continha de 9 a 15 pré-pupas cada um. Após a formação da câmara pupal, que ocorria em um ou dois dias, os potes foram abertos noterceiro dia verificandose e registrando-se a presença de pupas ou pré-pupas, presentes nas câmaras, diariamente.

\subsubsection{Estágio adulto}

Nas observações da fase adulta foram considerados os seguintes parâmetros: períodos de pré-oviposição, oviposição e pós-oviposição, total de ovos depositados semanalmente por fêmea, viabilidade dos ovos, longevidade de machos e fêmeas e razão sexual. 
Para as determinações na fase adulta, utilizaram-se 27 casais de $P$. pertinax emergidos no mesmo dia, em cópula, obtidos dos ensaios da fase larval; destes foram considerados 19 casais que realizaram posturas, pois poderia ter havido falha na seleção dos casais em cópula, devido não ser observável dimorfismo sexual. Os adultos eram colocados, por casal, em copos plásticos com tampa de acrílico, com capacidade de $50 \mathrm{ml}$; a alimentação foi preparada e oferecida da mesma maneira que para as larvas.

Diariamente os ovos produzidos eram colhidos, recortados das folhas com tesoura e transferidos para recipientes plásticos, com $10 \times 24 \mathrm{~cm}$, contendo 75 repartições de $1,5 \times 1,5 \times 1,5$ cm, tapados com placas de vidro de $3,0 \times 9,5 \mathrm{~cm}$, com o auxílio de um elástico, para observação da viabilidade.

Foi registrado o número do casal, data da emergência, data das posturas, número de ovos diários, data da eclosão das larvas, número de larvas que eclodiram e morte dos machos e das fêmeas.

Ovos, pupas e adultos, machos e fêmeas, provenientes dos experimentos, foram medidos utilizado-se o microscópio estereoscópico acoplado a um aparelho digital, composto de ocular WILD TYP325400 e central de processamento WILD MMS 235 , com precisão de $0,01 \mathrm{~mm}$, e observado o seu aspecto. 
Para a determinação da razão sexual utilizaram-se 100 adultos produzidos na criação estoque, os quais eram dissecados e observada a genitália.

\subsubsection{Tabela de vida de fertilidade}

A partir das informações biológicas obtidas foi elaborada uma tabela de vida de fertilidade, seguindo-se a metodologia descrita por SILVEIRA NETO et alii (1976).

Foram calculados os parâmetros: Taxa líquida de reprodução (Ro), Duração média de uma geração (T), Capacidade de aumentar em número (rm) e Razão finita de aumento $(\lambda)$. 


\section{RESULTADOS E DISCUSSÃO}

\subsection{Especificidade hospedeira}

Consultas à coleção entomológica do Museu de Entomologia do Instituto Biológico de São Paulo, em São Paulo,SP, revelaram exemplares de $P$. pertinax provenientes de Leme, SP; Ipanema, SP; Goiatuba, GO; Jarinú, SP; São José dos Campos, SP e Parreiras, RJ; e sobre B. pilosa material de Belo Horizonte, MG. No Museu da Seção de Entomologia Fitotécnica do Instituto Agronômico, em Campinas, SP, foram verificados insetos desta espécie provenientes de Sorocaba, SP, coletados em fumo; de Piracicaba, SP, sobre gergelim; de Campinas, SP, coletados sobre algodoeiro, soja, paineira e nogueira pecan, e material proveniente de Pompéia, SP. Entretanto, só foi registrado atacando folhas de algodoeiro e de nogueira pecan, em Campinas, SP.

Com estas observações e as constantes na literatura sobre as espécies vegetais atacadas por Phaedon spp., foram realizados os ensaios para a verificação da especificidade hospedeira de $P$. pertinax. 


\subsubsection{Alimentação de larvas e adultos}

Nos testes de não-preferência utilizando-se larvas de 1 - instar de $P$. pertinax foram avaliadas 66 plantas (TABELA 1), sendo que em 41 destas $(62,12 \%)$ não ocorreu sequer tentativa de alimentação, havendo dispersão das larvas, e em dois ou três dias a mortalidade era total; a planta no 64, N. tabacum (fumo), apresentou efeito tóxico por contato, com $100 \%$ de mortalidade no primeiro dia; a planta no 18, Tagetes sp., não foi incluída neste teste, pôr ser do mesmo gênero que a no 17 . Alimentação exploratória insignificante ocorreu nas plantas n오 $4,11,12,16$, $20,28,30,34,36,39,49$ e 56 (TABELA 3), com mortalidade

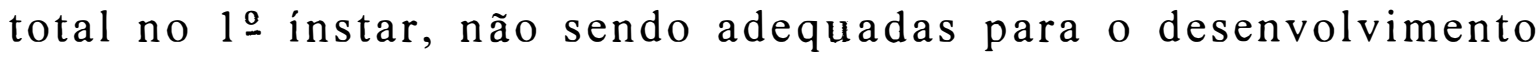
larval.

Nas espécies C. endivia (1), E. alba (29) e T. speciosa (38) poucas larvas conseguiram atingir o 2 o instar, mostrando uma alimentação bastante deficiente, e com mortalidade total no 3o instar. Um nível alimentar moderado foi observado nas plantas $T$. erecta (17), C. sulphureus (25), H. annuus (37) e B. campestris (48). No entanto, para as espécies nas 37 e 48 a viabilidade larva-adulto foi de apenas $1 \%$; os adultos morreram 
em poucos dias mesmo mantendo-se a sua alimentação na planta teste (TABELA 3). C. sulphureus mostrou um efeito de antibiose; apesar das larvas se alimentarem moderadamente da planta não houve sobreviventes no primeiro ínstar. $T$. erecta resultou em uma viabilidade larva-adulto de $10 \%$ porém, observando os adultos obtidos, na mesma planta durante trinta dias, notaram-se algumas posturas com ovos viáveis, sobrevivendo somente dois adultos até o final deste período, indicando fraca possibilidade de criação de $P$. pertinax nesta espécie de planta.

Todas as espécies de Bidens (21 a 24) revelaram-se adequadas para a alimentação do inseto, com viabilidade larvaadulto maior que $85 \%$. Coreopsis sp. mostrou-se semelhante à Bidens spp., com viabilidade de 78\% (TABELA 3); os gêneros Cosmos e Coreopsis são pertencentes à tribo Heliantheae e próximos de Bidens; encontram-se espécies destes gêneros citadas como pertencentes a Bidens spp.

Os resultados dos testes de alimentação com adultos, sem chance de escolha, indicaram que das 67 plantas (TABELA 1) somente em $14(20,90 \%)$ houve procura alimentar, nas demais não foram observados sinais de alimentação, e em vinte dias a grande maioria já estava morta. 
TABELA 3. Teste de alimentação Phaedon pertinax stal sem chance de escolha.

com larvas de 1 o instar de em diferentes plantas, de $70 \pm 10 \%$; fotofase 12 - 14 horas.

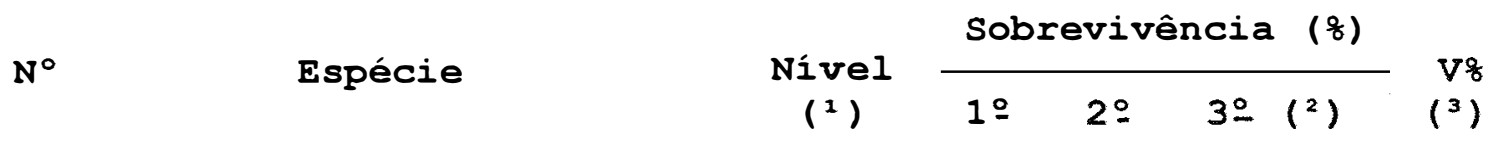

1 Cichorium endivia

4 Chaptalia nutans

11 Eupatorium pauciflorum

12 Emilia sonchifolia

16 Porophyllum ruderale

17 Tagetes erecta

20 Ambrosia polystachya

21 Bidens gardneri

22 Bidens pilosa

23 B.pilosa (=subalternans)

24 Bidens rubifolia

25 Cosmos sulphureus

28 Schkuhria pinnata

29 Eclipta alba

30 Galinsoga parviflora

34 Blainvillea biaristata

35 Coreopsis sp.

36 Dahlia sp.

37 Helianthus annuus

38 Thitonia speciosa

39 Pterocaulon alopecuroides

40 Matricaria sp.

48 Brassica campestris

$49 R$. nasturtium-aquaticum

56 Allium cepa

$\begin{array}{rrrrr}++ & 4 & 2 & 0 & 0 \\ + & 0 & & & 0 \\ + & 0 & & & 0 \\ + & 0 & & & 0 \\ + & 0 & & & 0 \\ +++ & 62 & 36 & 26 & 10 \\ + & 0 & & & 0 \\ ++++ & 95 & 93 & 87 & 85 \\ ++++ & 95 & 93 & 92 & 89 \\ ++++ & 98 & 95 & 90 & 88 \\ ++++ & 97 & 96 & 89 & 88 \\ +++ & 0 & & & 0 \\ + & 0 & & & 0 \\ ++ & 2 & 1 & 0 & 0 \\ + & 0 & & & 0 \\ + & 0 & & & 0 \\ ++++ & 92 & 90 & 82 & 78 \\ + & 0 & & & 0 \\ +++ & 11 & 5 & 2 & 1 \\ ++ & 4 & 0 & & 0 \\ + & 0 & & & 0 \\ ++ & 7 & 1 & 0 & 1 \\ +++ & 29 & 8 & 2 & 0 \\ + & 0 & & & \end{array}$

(1) Niveis de alimentação (TABELA 2) $+=$ Alimentação exploratória; $++=$ Fraco (poucas larvas no $2 \circ$ instar); $+++=$ Moderado; $++++=$ Normal.

(2) Instares

(3) Viabilidade (larva até emergência de adultos) 
As espécies E. sonchifolia (12), P. ruderale (16), Dahlia sp. (36) e T. speciosa (38) mostraram uma alimentação insignificante, com baixa sobrevivencia aos 10 dias e mortalidade total aos 20 dias de exposição (TABELA 4). Fraca reação alimentar ocorreu para Matricaria sp. (40) e A. cepa (56), com uma sobrevivência aos 10 dias de apenas $10 \%$ dos insetos; aos 30 dias todos morreram.

Em Tagetes spp. (17 e 18) e C. sulphureus (25) ocorreu uma alimentação moderada. No entanto, da mesma forma que para as larvas (TABELAS 3 e 4), houve efeito de antibiose em $C$. sulphureus não existindo sobreviventes após 20 dias de exposição, e para Tagetes spp. o indice de sobrevivência (25\%), após 20 dias, foi muito reduzido.

Bidens spp. (21 a 24) e Coreopsis sp. (35) mostraramse nutricionalmente adequadas para $P$. pertinax, havendo um nível de alimentação normal e altos valores de sobrevivência (TABELA 4).

Os adultos foram mais seletivos do que as larvas de $1^{\circ}$ ínstar, já que todas as 14 plantas utilizadas pelos adultos (TABELA 4), também o foram pelas larvas (TABELA 3), além de outras 11 plantas que estas se alimentaram. 
TABELA 4. Teste de alimentação com adultos de Phaedon pertinax stal em diferentes plantas, sem chance de escolha. Temperatura $25 \pm 3^{\circ} \mathrm{C}$; UR de 70 \pm 108 ; fotofase $12-14$ horas.

\begin{tabular}{|c|c|c|c|c|c|}
\hline \multirow{2}{*}{$N^{\circ}$} & \multirow{2}{*}{ Espécie } & \multirow{2}{*}{$\begin{array}{c}\text { Nível } \\
\text { (') }\end{array}$} & \multicolumn{3}{|c|}{ Sobrevivência $\left(\frac{q}{8}\right)$} \\
\hline & & & 5 & 10 & 20 (dias) \\
\hline 12 & Emilia sonchifolia & + & 65 & 25 & 0 \\
\hline 16 & Porophyllum ruderale & + & 45 & 0 & 0 \\
\hline 17 & Tagetes erecta & +++ & 55 & 35 & 25 \\
\hline 18 & Tagetes sp. & +++ & 40 & 30 & 25 \\
\hline 21 & Bidens gardneri & +++ & 100 & 100 & 95 \\
\hline 22 & Bidens pilosa & ++++ & 100 & 100 & 100 \\
\hline 23 & B.pilosa (=subalternans) & ++++ & 100 & 95 & 95 \\
\hline 24 & Bidens rubifolia & $t++t$ & 100 & 100 & 100 \\
\hline 25 & Cosmos sulphureus & +++ & 95 & 10 & 0 \\
\hline 35 & Coreopsis sp. & ++++ & 100 & 100 & 95 \\
\hline 36 & Dahlia sp. & + & 60 & 10 & 0 \\
\hline 38 & Thitonia speciosa & + & 40 & 10 & 0 \\
\hline 40 & Matricaria sp. & ++ & 80 & 50 & 10 \\
\hline 56 & Allium cepa & ++ & 90 & 40 & 10 \\
\hline
\end{tabular}

( $\left.{ }^{2}\right)$ Níveis de alimentação (TABELA 2) $+=$ Insignificante; $++=$ Fraco; $+++=$ Moderado; $++++=$ Normal. 
Das espécies citadas na literatura como hospedeiras de $P$. pertinax, tanto para larvas como adultos, só houve alimentação em $B$. pilosa, concordando com as citações de LIMA (1936, 1953 e 1955), RIBEIRO (1953) e SILVA et alii (1968), para esta planta.

As ocorrências relatadas por MENDES (1938b) em $G$. hirsutum (algodoeiro), por SILVA et alii (1968) em $S$. brasiliensis (Maria mole), G. hirsutum e $V$. vinifera (videira) e as referências em coleções entomológicas dos museus consultados, em $C$. ellinoensis (nogueira pecan), Chorisa sp. (paineira), G. $\max$ (soja), N. tabacum (fumo) e $S$. indicum (gergelim) são discordantes com os resultados desta pesquisa, pois o inseto em nenhuma de suas fases de desenvolvimento se utilizou destas plantas.

Nos gêneros ou espécies de plantas onde BERTELS (1953 e 1962), mencionou P. confine sobre S. brasiliensis, Z. mays (milho) e S. tuberosum (batata-inglesa); e Bosq ', citado por MORÁN LEMIR (1983), relatou $P$. affine sobre Baccharis serrulata e COX (1991) citou $P$. armoraciae e $P$. cochleariae, sobre $R$. nasturtium-aquaticum (agrião-d'água), e

\footnotetext{
1 BOSQ, J.M. Segunda lista de Coléopteros da la República Argentina, dañinos a la agricultura. Min. Agric. Nac., Dir. San. Veg., Div. Zool. Agric.. 80 pp., 1942.
} 
P. cochleariae sobre B. campestris (mostarda), somente ocorreu alguma alimentação de larvas de $P$. pertinax sobre mostarda, entretanto para Tagetes sp. e Bidens sp., plantas citadas por MORÁN LEMIR (1983) como hospedeiras secundárias de $P$. consimile, houve resposta positiva de $P$. pertinax.

\subsubsection{Postura e danos}

As avaliações dos testes de não-preferência para oviposição (TABELA 5), revelaram que quando não houve chance de escolha a $B$. pilosa somente ocorreu colocação de ovos importante em Coreopsis sp., porém em número reduzido (52) quando comparado com o teste com chance de escolha (219) e a B. pilosa (697 ovos). Das 62 plantas avaliadas ocorreu postura em $6(9,7 \%)$, mostrando. que há retenção de ovos quando as plantas não são adequadas para a alimentação do inseto; a média de ovos postos de maneira aleatória, por pressão de oviposição e quase sempre sem cobertura fecal, nas placas de petri foi de 7,9 em 13 observações.

No teste com chance de escolha, o número de plantas onde ocorreu oviposição foi maior do que no teste sem chance, sendo que das 63 plantas testadas houve posturas em 31 (49,2\%), e o número médio de ovos postos aleatoriamente nas placas de Petri foi de 10,6. Nas plantas $T$. erecta e Matricaria sp. a postura foi reduzida em comparação à realizada em $B$. pilosa. 
A postura nas plantas C. sulphureus e Coreopsis sp. foi moderada, indicando haver razoável efeito de atração por oviposição quando $B$. pilosa está presente como fonte de alimento. As outras plantas (TABELA 5), onde o número de ovos colocados foi bastante reduzido e menor que os postos de maneira aleatória, podem ser consideradas não atrativas para postura.

Os resultados obtidos (TABELA 6) para as avaliações de antixenose para postura e alimentação (índice de dano visual), nas espécies do gênero Bidens e Coreopsis sp, mostraram que $B$. rubifolia foi a planta mais preferida, diferindo estatisticamente das demais espécies. Para nível alimentar $B$. gardneri e $B$. pilosa foram semelhantes entre si, indicando uma alimentação moderada, porém diferiram estatisticamente de $B$. pilosa $(=$ subalternans) e Coreopsis sp., que apresentaram notas de dano baixas e iguais entre si. $\quad$ B. pilosa ( = subalternans ) foi a planta menos preferida para postura, no entanto não diferiu estatisticamente de $B$. gardneri e $B$. pilosa. Dentre as plantas onde o número de ovos postos foi intermediário, Coreopsis sp. mostrou-se mais atrativa que B. pilosa (= subalternans). 
TABELA 5. Teste de postura com Phaedon pertinax stal em diferentes plantas, com e sem chance de escolha a Bidens pilosa. Temp. $25 \pm 3{ }^{\circ} \mathrm{C}$; UR de $70 \pm 10 \%$; fotofase 12-14 horas.

$\mathrm{N}^{\circ} \quad$ Espécie

Número total de ovos

Clescolha s/escolha

\begin{tabular}{|c|c|c|c|}
\hline 1 & Cichorium endivia & 1 & - \\
\hline 4 & Chaptalia nutans & 2 & - \\
\hline 6 & Gazania sp. & 2 & - \\
\hline 7 & Cynara scolymus & 1 & - \\
\hline 8 & Vernonia polyanthes & 1 & - \\
\hline 10 & Mikania cordifolia & 2 & - \\
\hline 12 & Emilia sonchifolia & 2 & - \\
\hline 13 & Senecio brasiliensis & 2 & 2 \\
\hline 14 & Senecio spl. & 1 & - \\
\hline 15 & Senecio sp2. & 3 & - \\
\hline 16 & Porophyllum ruderale & 1 & - \\
\hline 17 & Tagetes erecta & 16 & - \\
\hline 19 & Xanthium cavanillesii & - & 1 \\
\hline 22 & Bidens pilosa & $697 \quad\left({ }^{1}\right)$ & (np) \\
\hline 25 & Cosmos sulphureus & 262 & 8 \\
\hline 26 & Acanthospermum australe & 2 & - \\
\hline 28 & Schkuhria pinnata & 1 & - \\
\hline 29 & Eclipta alba & 1 & - \\
\hline 30 & Galinsoga parviflora & 2 & - \\
\hline 32 & Tridax procumbens & 1 & - \\
\hline 33 & Wedelia paludosa & 5 & - \\
\hline 35 & Coreopsis sp. & 219 & 52 \\
\hline 40 & Matricaria sp. & 15 & 6 \\
\hline 41 & Chrysanthemum sp. & 2 & - \\
\hline 42 & Calendula sp. & 1 & - \\
\hline 45 & Aster squamatus & 8 & - \\
\hline 48 & Brassica campestris & 4 & - \\
\hline 57 & Gossypium hirsutum & 6 & - \\
\hline 58 & Ficus carica & 1 & 1 \\
\hline 61 & Prunus persica & 3 & - \\
\hline 67 & Vitis vinifera & 1 & - \\
\hline
\end{tabular}

(1) Média de 13 observações

(np) Não presente no teste

Obs.: As outras espécies de Bidens $(21,23$ e 24) e Tagetes sp. (18) não foram testadas neste ensaio, e as Plantas da TABELA 1, onde a oviposição com ou sem chance de escolha foi nula, não foram listadas. 


TABEIA 6. Antixenose de Bidens spp. e coreopsis sp. a
Phaedon pertinax stal, em relação a postura
e alimentação. Temp. $25 \pm 3^{\circ} \mathrm{C}$ UR de $70 \pm 10 \% ;$
fotofase 14 horas.

Espécie de planta
Número de ovos

(1)
Nota de dano

$\left({ }^{2}\right)$

\begin{tabular}{|c|c|c|c|c|}
\hline Bidens rabifolia & 17,00 & A & 3,7 & A \\
\hline Bidens gardneri & 4,02 & BC & 1,9 & B \\
\hline Bidens pilosa & 5,86 & $\mathrm{BC}$ & 1,7 & B \\
\hline Coreopsis sp. & 8,50 & B & 0,8 & C \\
\hline B. pilosa (=subalternans) & 1,92 & C & 0,8 & C \\
\hline $\begin{array}{l}\text { D.M.S. } 18= \\
\text { CV } 8=\end{array}$ & \multicolumn{2}{|c|}{$\begin{array}{r}5,49 \\
47,44\end{array}$} & \multicolumn{2}{|c|}{$\begin{array}{r}0,57 \\
20,54\end{array}$} \\
\hline
\end{tabular}

Médias seguidas por letras distintas diferem entre si, pelo teste de Tukey, ao nivel de $1 \frac{8}{\text { de }}$ probabilidade.

(1) Número de ovos/fêmea/2 dias; média de 5 observações

$\left({ }^{2}\right)$ Nota de dano (TABELA 2); média de 5 observações 


\subsection{Aspectos biológicos de P. pertinax}

\subsubsection{Ovo}

É ovóide alongado, com córion liso brilhante, de coloração amarela, medindo em média $1,24 \pm 0,01 \mathrm{~mm}$ de comprimento por $0,54 \pm 0,004 \mathrm{~mm}$ de largura, com um intervalo de variação (IV) de 1,08 - 1,44 $\mathrm{mm}$ e de 0,48 - 0,63 $\mathrm{mm}$, respectivamente $(n=60)($ Figura 1 a 1$)$.

\subsubsection{Período de incubação e viabilidade}

A duração média do período de incubação foi de $7,3 \pm$ 0,1 dias $(\mathrm{IV}=6-8 ; \mathrm{n}=146)$, coeficiente de variação $(\mathrm{CV})=$ $7,9 \%$.

A viabilidade média na fase de ovo foi em média de $84,6 \pm 3,9 \%(\mathrm{IV}=68,4-100,0 ;$ em dez grupos [13-23 ovos], $\mathrm{n}=$ $174), \mathrm{CV}=14,7 \%$. 


\subsubsection{Larva}

As larvas recém-eclodidas de $P$. pertinax são de coloração negra, rompem o córion do ovo e permanecem agregadas iniciando em pouco tempo a alimentação (Figura 1a2). Durante o processo de muda adquirem coloração marrom e não se alimentam (Figura 1bl); a cada ecdise a larva fixa-se a folha pela extremidade posterior ocorrendo a ruptura da cápsula cefálica e da pele, longitudinalmente, permanecendo a exúvia aderida à folha.

Exteriormente apresentam o corpo coberto por pêlos e uma série de tubérculos glandulares retráteis em número par. No 1- ínstar estão presentes no mesotórax e metatórax, enquanto que no 2 e 3 o encontram-se também nos 7 primeiros segmentos abdominais (Figura 1b2). Quando as larvas são tocadas ocorre a liberação de um líquido viscoso, pelos tubérculos; considerado por RIBEIRO (1953) como de defesa.

As medições de comprimento para as larvas neonatas, faratas do 1ㅇ e do 2o ínstares, e no seu máximo desenvolvimento (início da fase de pré-pupa), foram em média de 1,$6 ; 2,7 ; 4,0$ e 7,3 mm (TABELA 7); RIBEIRO (1953) relatou comprimento de 7,0 $\mathrm{mm}$ para as larvas em fase final de desenvolvimento. 


\subsubsection{Determinação do número de ínstares}

As medições da cápsula cefálica das larvas de $P$. pertinax (TABELA 8) revelaram que esta espécie apresentou três instares larvais, medindo, em média, 0,5;0,7 e $1,2 \mathrm{~mm}$, para o $1 \stackrel{0}{2}$ - e 3o ínstares, respectivamente. A razão de crescimento, estabelecida pela regra de DYAR (1890), a qual indica uma relação no intervalo de 1,1 a 1,9 , para cada espécie, entre a largura da cápsula cefálica de dois ínstares subseqüentes, foi de 1,5 e 1,7 para a razão entre o 2 o e 1 o ínstares e 3 o e 2 ónstares, respectivamente; a média foi de 1,6.

\subsubsection{Duração e viabilidade larval}

A duração média dos diferentes ínstares larvais (TABELA 9), determinados a partir das datas de ocorrência de ecdises, foram de 3,$2 ; 3,0$ e 5,0 dias para o 1 은 2 을 3 instares, respectivamente $(\mathrm{n}=76)$; a duração média total do estágio larval foi de 11,1 dias. A viabilidade na fase de larva foi em média de $90,5 \pm 1,1 \%(I V=83,3-91,7$; em sete grupos [12 larvas], $\mathrm{n}=$ $84), \mathrm{CV}=3,2 \%$. 
TABELA 7. Variação média do comprimento (mm) das larvas de Phaedon pertinax stal. Temp., UR e fotoperíodo oscilantes.

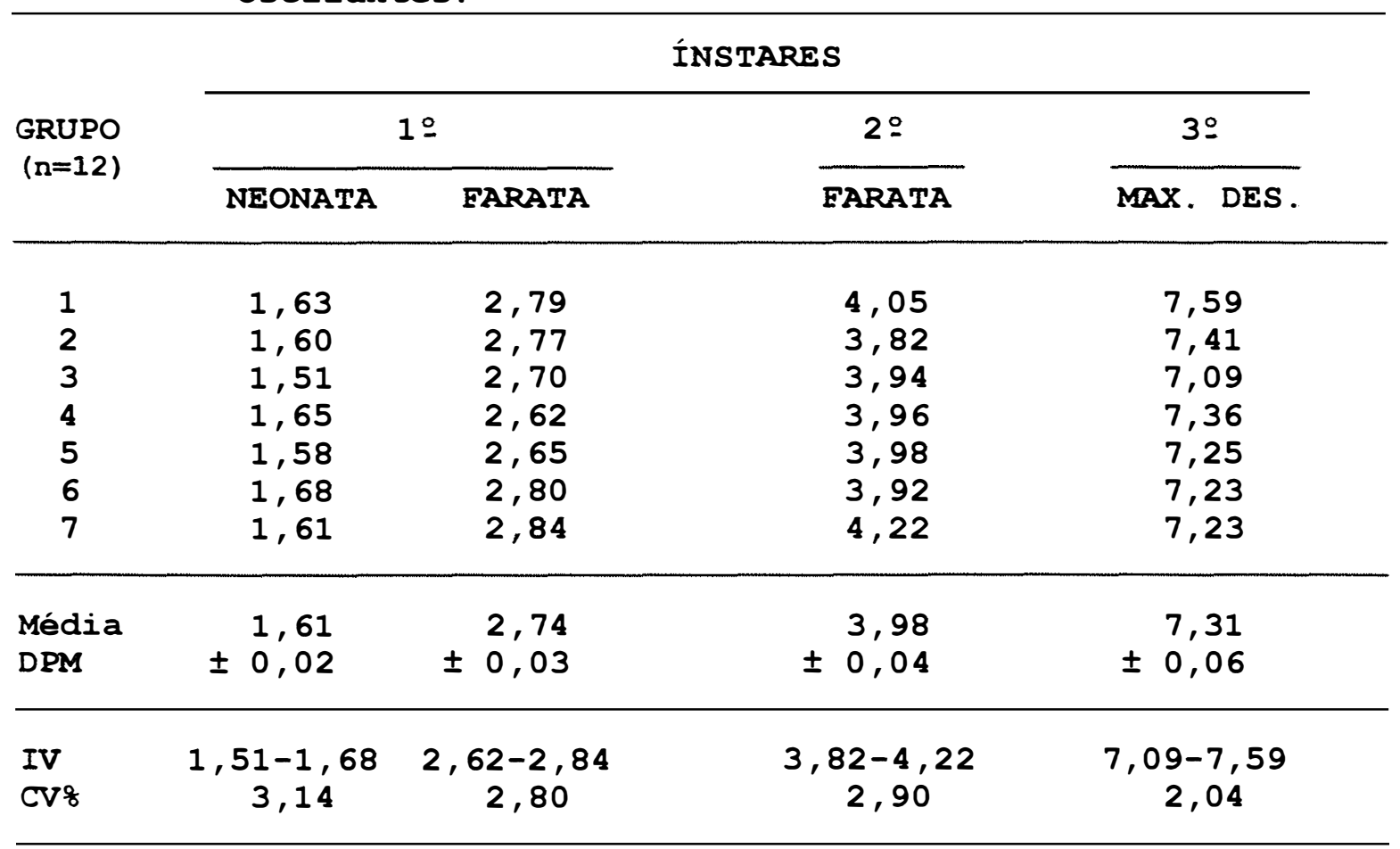

TABELA 8. Largura média das cápsulas cefálicas (mm) de Phaedon pertinax stal. Temperatura, UR e fotoperíodo oscilantes.

\begin{tabular}{|c|c|c|c|}
\hline \multirow{2}{*}{$\begin{array}{l}\text { GRUPO } \\
(n=12)\end{array}$} & \multicolumn{3}{|c|}{ ÍNSTARES } \\
\hline & 10 & 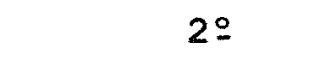 & 3 \\
\hline 1 & 0,486 & 0,720 & 1,212 \\
\hline 2 & 0,491 & 0,727 & 1,195 \\
\hline 3 & 0,486 & 0,732 & 1,184 \\
\hline 4 & 0,486 & 0,727 & 1,206 \\
\hline 5 & 0,489 & 0,732 & 1,222 \\
\hline 6 & 0,489 & 0,728 & 1,223 \\
\hline 7 & 0,489 & 0,727 & 1,217 \\
\hline Média & $0,49 \pm 0,001$ & $0,73 \pm 0,001$ & $1,21 \pm 0,005$ \\
\hline $\begin{array}{l}\text { IV } \\
\text { CV } 8\end{array}$ & $\begin{array}{c}(0,486-0,491) \\
0,37\end{array}$ & $\begin{array}{c}(0,720-0,732) \\
0,48\end{array}$ & $\begin{array}{c}(1,184-1,223) \\
1,13\end{array}$ \\
\hline
\end{tabular}




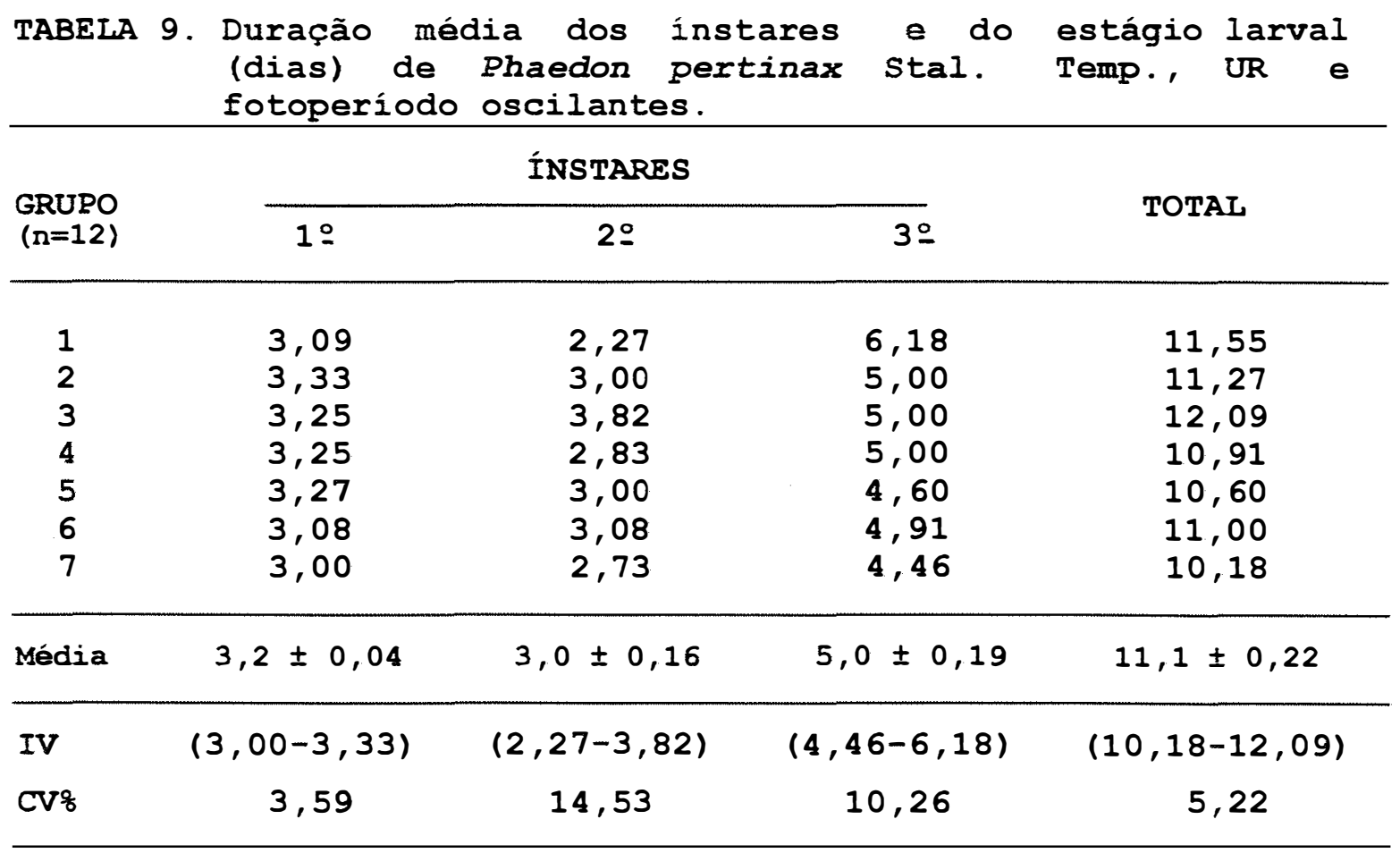

\subsubsection{Alimentação e danos}

As larvas de primeiro instar inicialmente alimentam-se da epiderme foliar de $B$. pilosa no lado inferior da folha, próximo ao local de postura (Figura 1a2); durante o desenvolvimento apresentam hábito gregário. Nos ínstares seguintes passam a se alimentar de toda a folha, fazendo perfurações irregulares e deixando somente as nervuras

principais (Figura 1b), provocando severo desfolhamento comprometendo floração e frutificação. Em altas infestações podem atacar o caule alimentando-se das partes verdes (Figuras 2 e 3 ). 
Em conseqüencia dos danos às folhas e caule freqüentemente a planta não consegue recuperar-se, emitindo raramente novas brotações, que também são danificadas enquanto houver larvas sobre a planta, ocorrendo posteriormente o secamento e a morte da planta.

Plântulas de $B$. pilosa também são atacadas por larvas dos diferentes ínstares, destruindo boa parte de uma sementeira natural.

\subsubsection{Pré-pupa e pupa}

Quando se inicia a fase de pré-pupa as larvas deixam a planta, mostrando um geotropismo positivo, dirigindo-se ao solo onde penetram a uma profundidade de 1-3 cm, formando uma câmara pupal. Algumas observações nesta fase foram realizadas em partes devido à dificuldade de manipulação, e a rara formação de pupas na ausência de solo. Os dados são parcialmente concordantes com os de RIBEIRO (1953), que observou a formação da câmara pupal a $1 \mathrm{~cm}$ de profundidade.

A pupa de $P$. pertinax (Figura lc) é do tipo livre, de coloração amarelo brilhante, medindo em média 4,3 $\pm 0,06 \mathrm{~mm}$ de comprimento por $2,8 \pm 0,03 \mathrm{~mm}$ de largura, IV $=3,2-4,8 \mathrm{~mm}$ e 2,5-3,2 mm e CV\% $=7,4$ e 6,0 , respectivamente $(\mathrm{n}=25)$. Não foi observado dimorfismo sexual nas pupas. 


\subsubsection{Duração e viabilidade}

A duração média do período de pré-pupa e pupa a emergência do adulto, foi de 13,6 $\pm 0,3$ dias (IV $=12,9-15,2 ; n$ $=67), \mathrm{CV}=5,3 \%$. A viabilidade nesta fase foi em média de $88,2 \pm 3,5 \%(I V=72,7-100,0 ;$ em sete grupos $[10-11$ prépupas], $\mathrm{n}=76), \mathrm{CV}=10,6 \%$.

A duração do período de pré-pupa foi determinado de maneira indireta, abrindo-se as câmaras pupais três dias após a penetração das larvas no solo; observando que a sua formação ocorre em 1 ou dois dias. Verificou-se uma duração média de 5,2 $\pm 0,1$ dias $(\mathrm{IV}=4-10$ dias, em 15 grupos [9-15 larvas], $\mathrm{n}=$ $185), C V=13,6 \%$; com viabilidade de $75,1 \%$ para pré-pupa e de $59,7 \%$ para pupa. Comparando-se este resultado com a viabilidade obtida quando não houve manuseio das câmaras $(88,6 \%)$, verifica-se que os distúrbios provocados pela manipulação das pupas afeta a sua viabilidade.

O período de pré-pupa e pupa a emergência do adulto foi de 13,6 dias e o de pré-pupa de 5,2 dias, resultando indiretamente 8,4 dias para o período de pupa. Esse dado é coerente com a observação de RIBEIRO (1953), que encontrou 6 a 8 dias para este período. 
O ciclo total médio (ovo-adulto) foi de 32 dias $(I V=$ $29,1-35,3)$, com viabilidade de $67,5 \%$.

\subsubsection{Adulto}

O adulto recém-emergido é de coloração geral amarela, algumas horas depois os élitros adquirem tons escuros progredindo até a cor definitiva que varia do verde ao azul metálico (Figura 1d); os primeiros artículos das antenas, a cabeça, as pernas, os três últimos segmentos abdominais e as margens laterais do protórax são de cor ferrugínea. Estas observações são concordantes, em parte, com RIBEIRO (1953), que descreveu a cor geral do inseto.

As dimensões médias dos adultos, medindo-se o comprimento do protórax e élitros $(n=80)$, foram de 4,83 $\pm 0,03$ $\mathrm{mm}(\mathrm{IV}=4,18-5,22 \mathrm{~mm} ; \mathrm{CV}=4,19 \%)$ para as fêmeas e de 4,29 $\pm 0,03 \mathrm{~mm}(\mathrm{IV}=3,79-4,66 \mathrm{~mm} ; \mathrm{CV}=4,11 \%)$ para os machos. A comparação das médias, entre fêmeas e machos, pela aplicação do teste $t$, mostrou que as medições são significativamente diferentes entre si $(P<0,001)$. Entretanto, não foi observado dimorfismo sexual; as fêmeas freqüentemente são maiores que os machos, no entanto este não é um caráter fixo, encontrando-se alguns machos maiores que as fêmeas. 


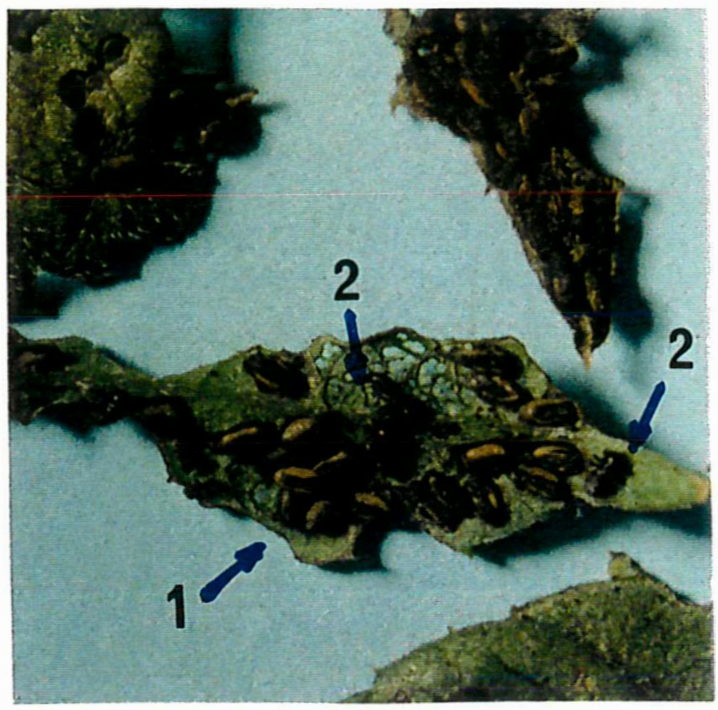

a $(x 4,0)$

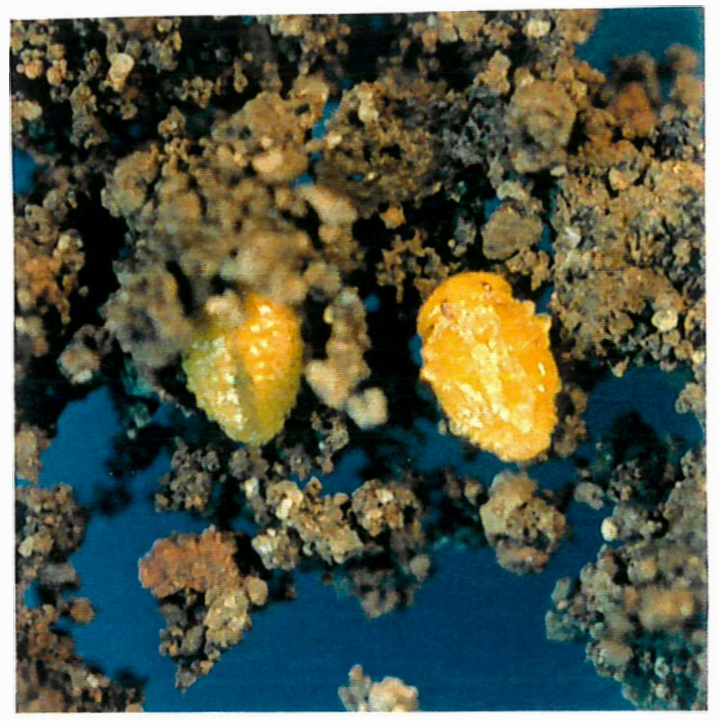

c $(x 4,4)$

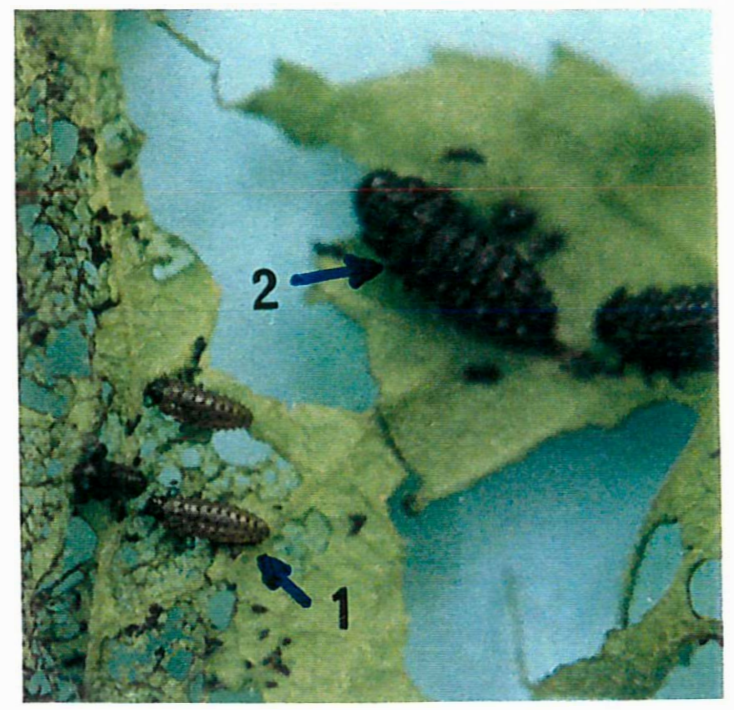

b $(x 3,0)$

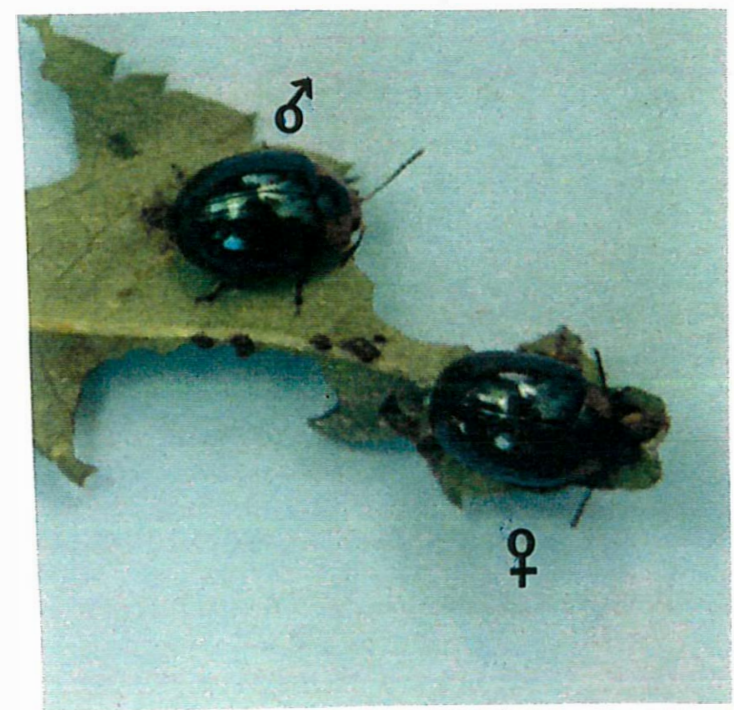

d $(x 4,0)$

Figura 1. Estágios do ciclo biológico de Phaedon pertinax Stal a) 1. posturas e 2. larvas neonatas; b) 1. larva farata do 2oínstar e 2. larva do 3-ínstar; c) pupa e d) adulto. 


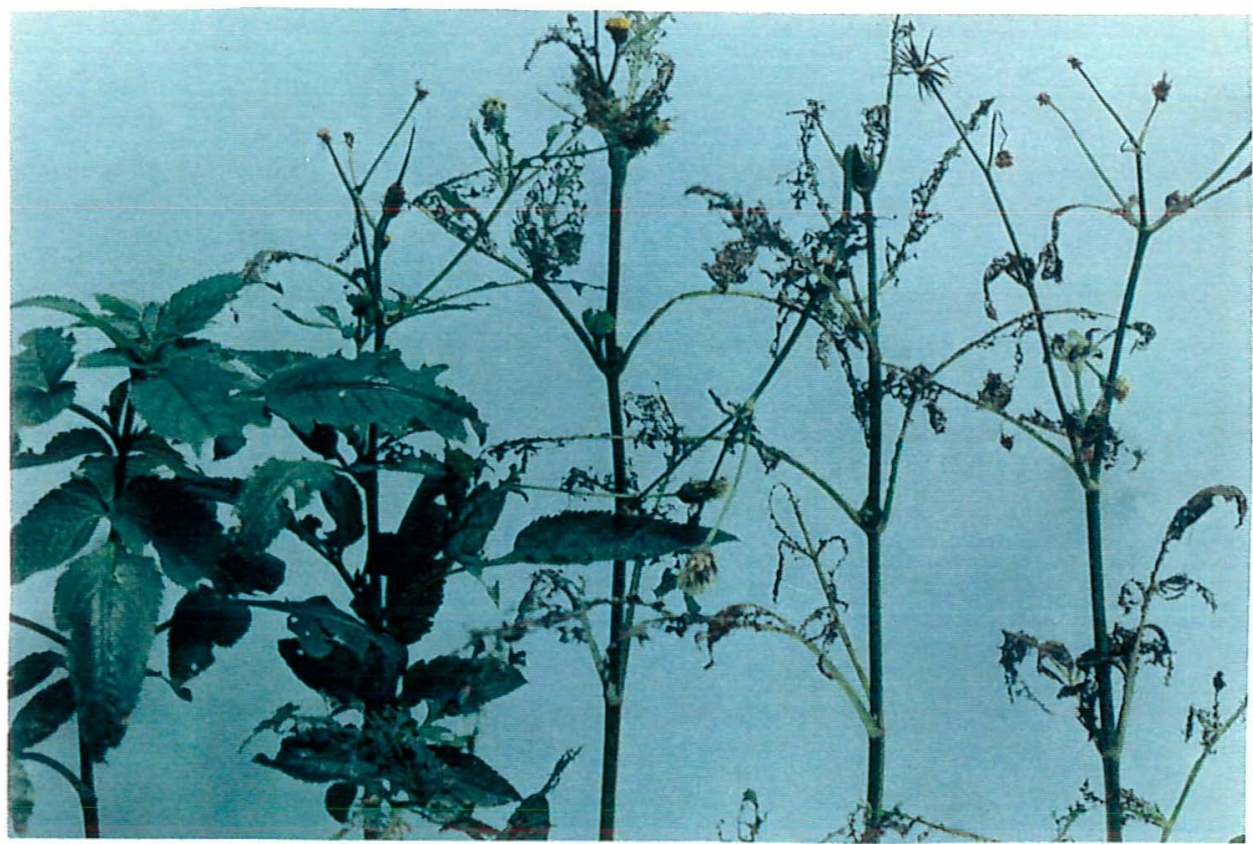

Figura 2. Evolução do ataque de larvas de Phaedon pertinax Stal a Bidens pilosa L.

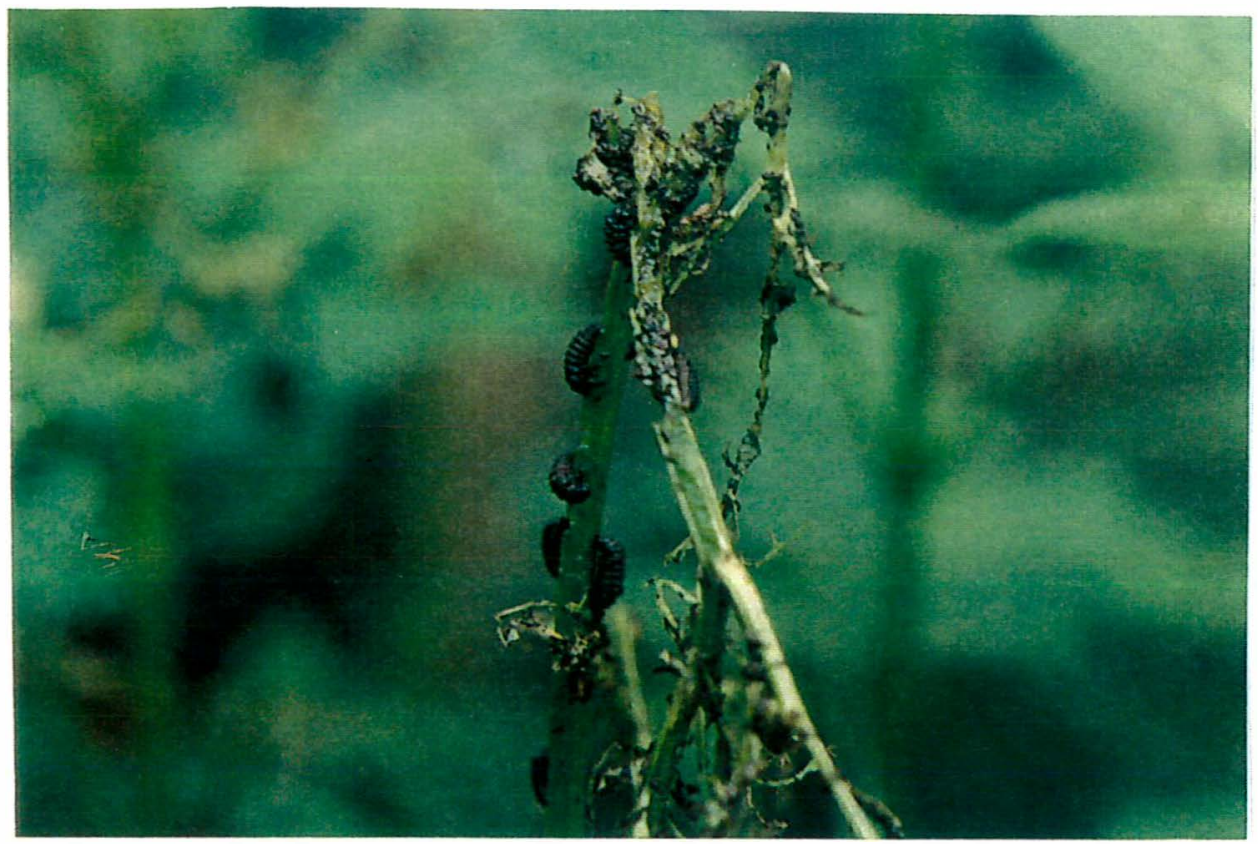

Figura 3. Danos severos de larvas do 3 ínstar de Phaedon Pertinax Stal ao caule de Bidens pilosa L. 


\subsubsection{Pré-postura, postura, longevidade e razão sexual}

pós-postura,

A duração média do período de pré-postura foi de 7,3 dias, de postura 124,7 dias e de pós-postura 25,3 dias (TABELA 10). A longevidade média para as fêmeas foi de $157,3 \pm 9,4$ dias $(\mathrm{IV}=62-222, \mathrm{CV}=26,1 \%)$ e para os machos de $187,6 \pm$ 11,7 dias $(\mathrm{IV}=102-300, \mathrm{CV}=27,3 \%)$.

A razão sexual, determinada por dissecação de 100 adultos da criação estoque, foi de 0,52 ; correspondendo a uma relação de sexos de 1 macho: 1 fêmea.

\subsubsection{Fecundidade e viabilidade dos ovos}

O número total de ovos, em média, postos por fêmea foi de $1279 \pm 101$ (IV $=388$ - 1950) e o número médio de ovos por semana por fêmea foi de $58 \pm 7$ (IV $=4-118)$. A viabilidade dos ovos na segunda semana de postura foi de $80,9 \pm 2,3 \%$ (IV $=$ $58,2-97,5 \% ; \mathrm{CV}=12,4 \%)$.

Durante o período máximo de postura, que é de 26 semanas (Figura 4), a maioria dos ovos (85\%) é colocada até a metade deste período. 


\subsubsection{Alimentação e reprodução}

Os adultos de $P$. pertinax se alimentam das folhas de B. pilosa em todo o ciclo fenológico da planta. O inseto prefere se alimentar dos folíolos mais jovens, no terço superior da planta. Os danos causados pelos adultos são insignificantes, recortam somente as bordas das folhas (Figura 5).

As atividades diurna e noturna são semelhantes; em repouso os adultos permanecem abrigados entre as folhas das brotações mais novas, preferencialmente na parte superior da planta. São encontrados caminhando pelas folhas, ou roendo o limbo foliar para alimentação, ou em oviposição na face ventral dos folí olos (Figura 1d). Os ovos são colocados em grupos (Figura 1al) ou raramente isolados, preferencialmente no ápice das folhas ou nas bordas. São em número bastante variável (TABELA 11), e as fêmeas os recobrem com suas dejeções fecais, para a sua fixação à folha.

Nas folhas onde anteriormente foi realizada postura ou se encontram larvas em alimentação, não se observam adultos realizando postura ou se alimentando. Quando tocados imobilizam-se e caem ao solo, são freqüentemente observados caminhando no solo para procura de abrigo, de plântulas ou de plantas adultas. Nas horas mais quentes do dia são dificilmente observados, pois abrigam-se sob folhas ou detritos do solo. 
No período chuvoso, raramente observam-se adultos voando; em insetos de laboratório, deixados alguns dias sem alimentação e posteriormente liberados no campo sobre $B$. pilosa, pôde-se observar hábito de vôo, entretanto somente poucos voam procurando emigrar ou voar de uma planta à outra.

O período de cópula é muito variável, podendo durar alguns minutos ou até mesmo várias horas; é freqüente encontrarem-se casais em cópula tanto durante o dia quanto à noite, e em qualquer horário.

TABELA.10. Duração média dos períodos de pré-postura, de postura, de pós-postura de Phaedon pertinax stal (dias). Temp., UR e fotoperiodo oscilantes.

\begin{tabular}{lrcc}
\hline $\begin{array}{c}\text { PERÍdo } \\
\text { (dias) }\end{array}$ & $\begin{array}{c}\text { Média } \\
(n=19)\end{array}$ & IV & CV \& \\
\hline & $7,3 \pm 0,3$ & $6-10$ & 17,2 \\
Pré-postura & $124,7 \pm 8,6$ & $32-177$ & 30,0 \\
Postura & $25,3 \pm 5,3$ & $1-67$ & 91,2 \\
Pós-postura & & & \\
\hline
\end{tabular}


TABEIA 11. Número médio de ovos de Phaedon pertinax stal postos por foliolo de Bidens pilosa (L.), em diferentes localidades do Estado de São Paulo.

Localidade (data)

n

Número de ovos

\begin{tabular}{lcccc} 
(data) & n & Média & IV & CV8 \\
\hline $\begin{array}{l}\text { Ubatuba } \\
(13-11-94)\end{array}$ & 54 & $8,59 \pm 0,80$ & $1-26$ & 68,21 \\
$\begin{array}{l}\text { Mogi-das-Cruzes } \\
(28-01-95)\end{array}$ & 126 & $7,23 \pm 0,55$ & $1-45$ & 85,00 \\
$\begin{array}{l}\text { Campinas } \\
(10-11-94)\end{array}$ & 56 & $12,80 \pm 1,52$ & $1-52$ & 88,93 \\
\hline
\end{tabular}

\subsubsection{Tabela de vida de fertilidade}

Para o estabelecimento da fertilidade de $P$. pertinax, os cálculos dos parâmetros avaliados revelaram que:

A duração média de uma geração (T), que representa o tempo médio entre a emergência dos adultos e o nascimento dos descendentes, foi de 13,75 semanas.

A taxa líquida de reprodução (Ro), mostrou que a população desta espécie pode aumentar 445,03 vezes em cada geração.

O valor da capacidade de aumentar em número ( $\mathrm{rm}$ ) foi de 0,44 , resultando uma razão finita de aumento ( $\lambda$ ) igual a 1,56, que representa o número de fêmeas acrescentado à população por fêmea por semana. 


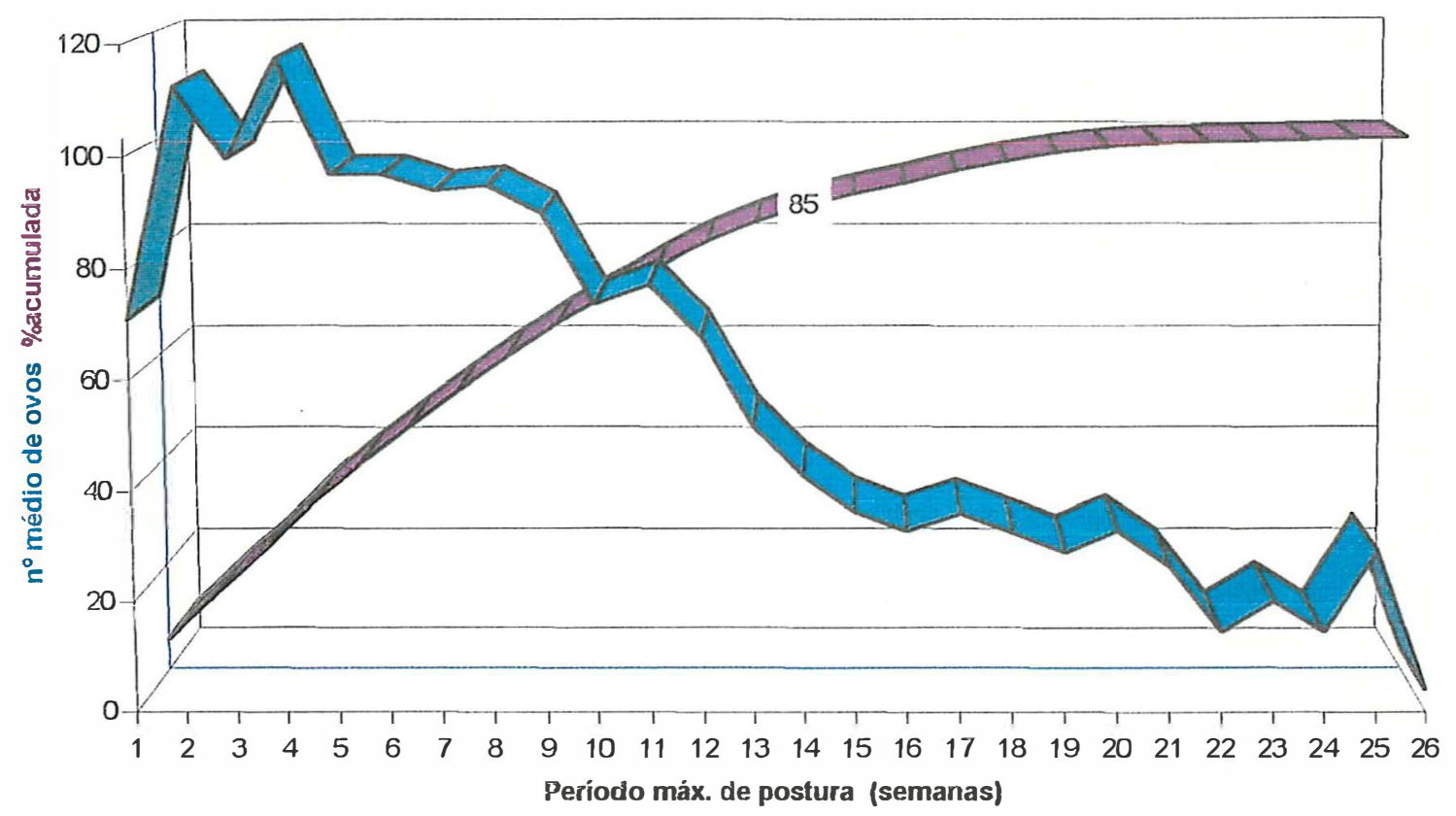

Figura 4. Ritmo de postura semanal e porcentagem acumulada de ovos postos por fêmea de Phaedon pertinax Stal, em Bidens pilosa L.

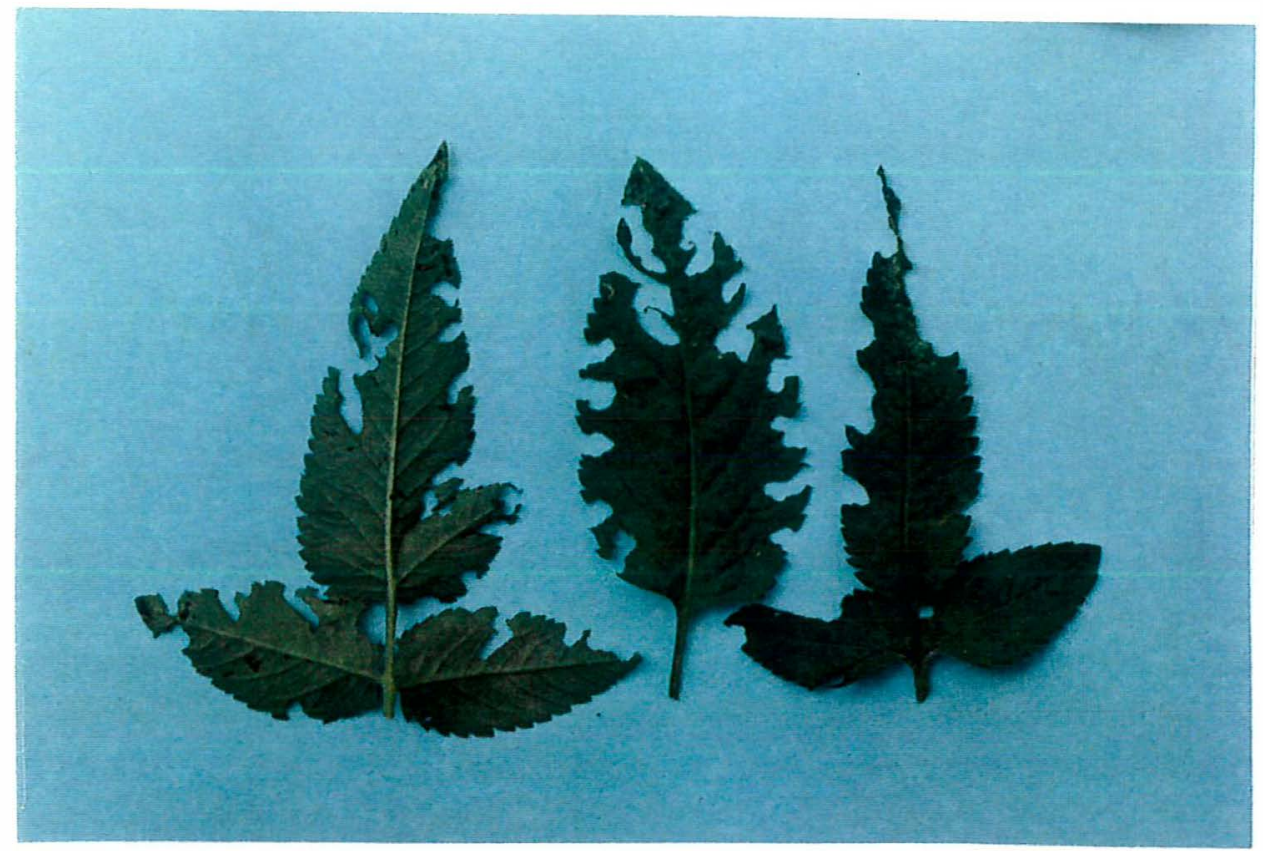

Figura 5. Folhas de Bidens pilosa L., com as bordas dos folíolos recortadas por adultos de Phaedon pertinax Stal. 


\subsection{Inimigos naturais}

Durante o desenvolvimento do trabalho, foram coletadas diversas amostras de posturas de $P$. pertinax provenientes de Mogi das Cruzes-SP, Ubatuba-SP, Campinas-SP e Bragança Paulista-SP, totalizando 1.236 ovos; nestas observações não se encontraram parasitóides de ovos. Entretanto, em todas as localidades observou-se a presença do predador Stiretrus erythrocephalus (Lepel. \& Serv., 1825) (Hemiptea-Heteroptera, Pentatomidae) (Figura 6), que se alimenta das larvas e adultos do inseto; a maior parte de sua população mostra mimetismo com a presa.

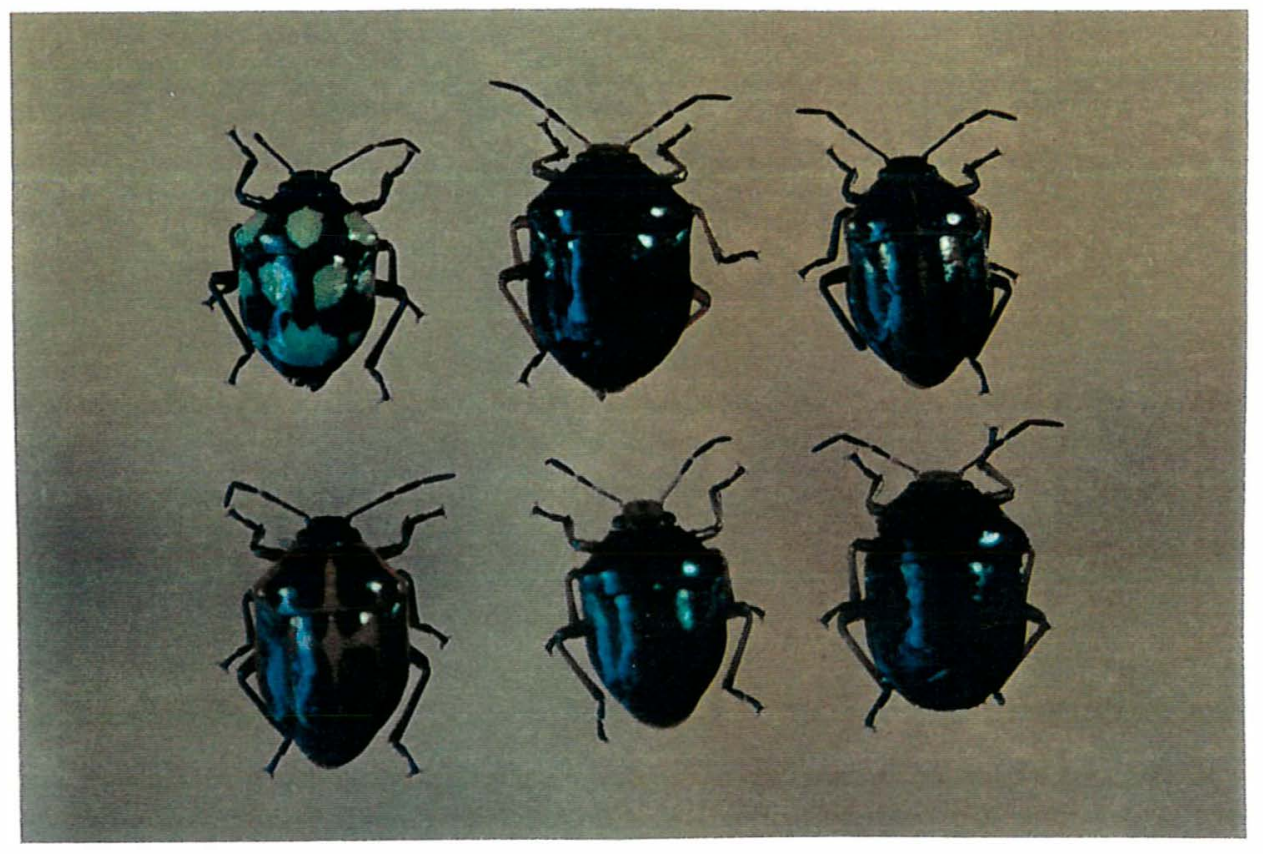

Figura 6. Adultos do predador Stiretrus erythrocephalus (Lepel. \& Serv., 1825). (x 2,5) 


\subsection{Avaliação como agente de controle biológico}

Pela pesquisa realizada, observando-se os critérios sugeridos por HARRIS \& ZWOLFER (1968) e WAPSHERE (1975), P. pertinax mostrou não se desenvolver nas plantas de interesse econômico avaliadas. Para as plantas ornamentais pode haver algum risco para Coreopsis sp., no entanto não há relatos anteriores de sua ocorrência nesta planta, e o inseto adulto, em condições de laboratório e sem chance de escolha, coloca poucos ovos e mesmo em presença $B$. pilosa os danos são moderados (TABELAS 5 e 6 ).

Testes exploratórios de campo com plantas em vasos ou em jardins, através de várias liberações de insetos, mostraram que os adultos de $P$. pertinax provocam poucos danos às folhas e flores de C. sulphureus, raramente realizando posturas nas folhas preferindo migrar. No caso de T. erecta, não há sequer a permanência dos insetos, que em pouco tempo migram sem se alimentarem ou realizarem posturas. Para Coreopsis sp., observou-se um dano fraco à planta e poucas posturas, entretanto somente alguns adultos permanecem na planta e após o ataque ocorre a recuperação destas.

Avaliando-se a eficácia potencial do inseto como candidato a agente de controle biológico de plantas daninhas, através do sistema de valores proposto por HARRIS (1973) e 
modificado por GOEDEN (1983), dentro dos parâmetros que foram estudados, o inseto obteve boas pontuações para avaliação inicial da capacidade inata de dano ( 23 ) e adequação de uso como agente de controle biológico (17), mostrando-se, nestes aspectos, similar a Chrysolina hyperici Forst. (Coleoptera, Chrysomelidae), com (28) e (22) pontos, respectivamente (GOEDEN, 1983).

Pelas observações realizadas nos diferentes testes, $P$. pertinax mostrou ser um inseto oligófago, desenvolvendo-se de maneira satisfatória em Bidens spp. (Figura 7), restrito a poucas espécies da tribo Heliantheae, concordando com o relato de COX (1991), que considera certas espécies do gênero Phaedon com valor para o controle biológico de várias espécies de plantas invasoras. 


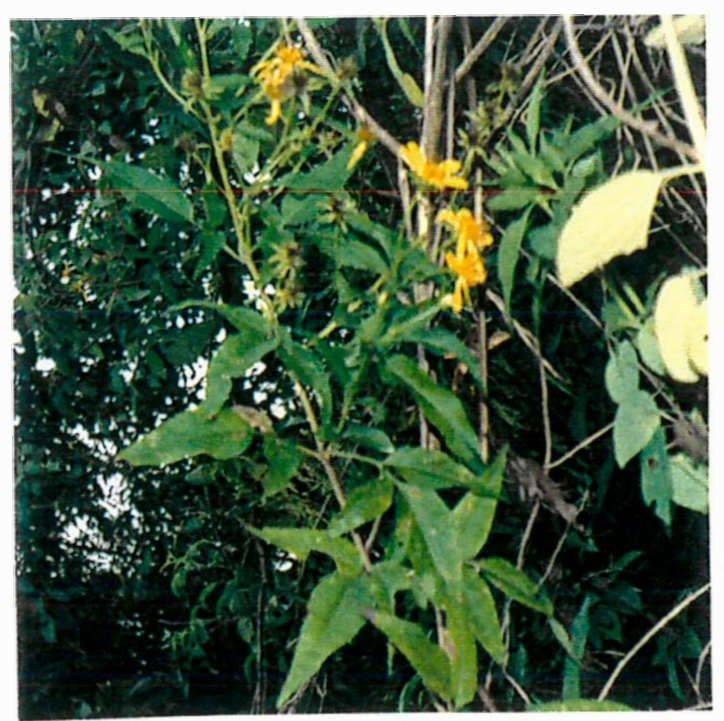

A

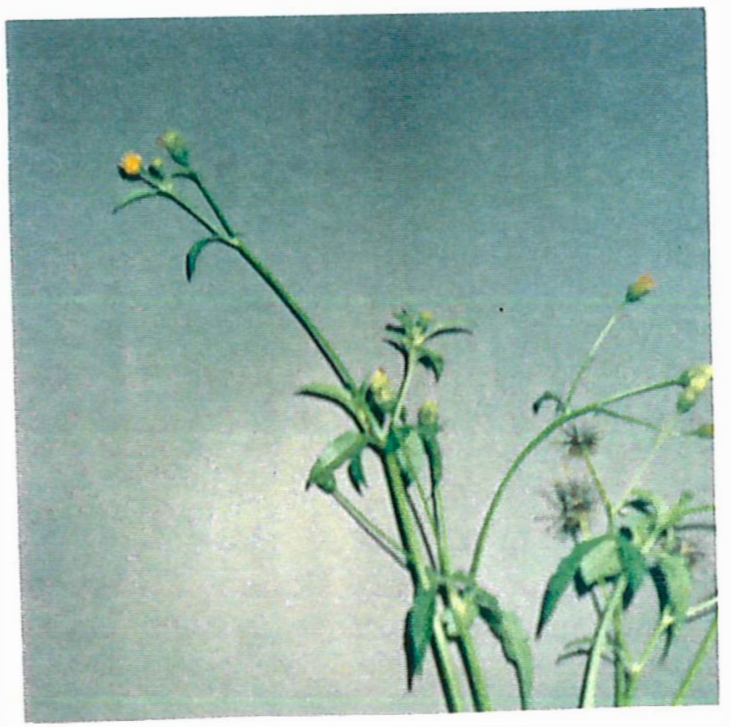

C

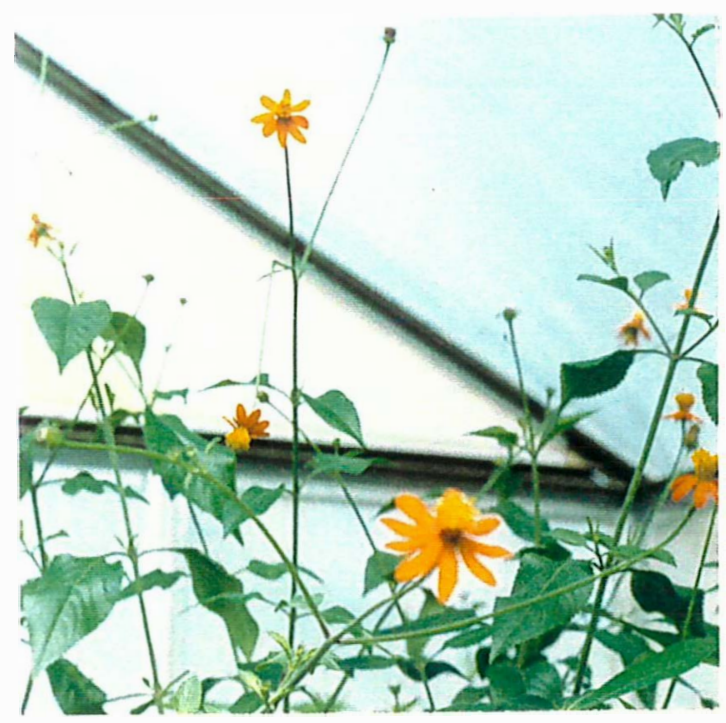

B

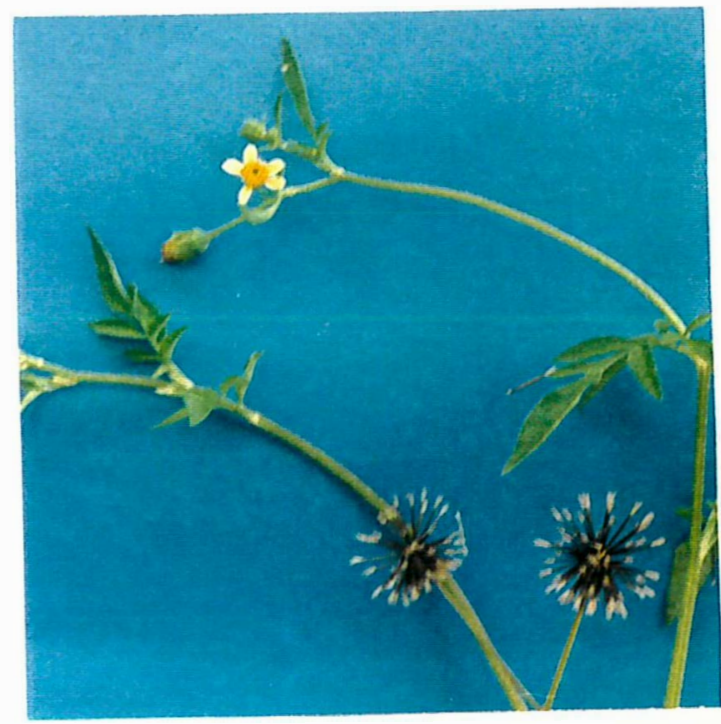

D

Figura 7. A) Bidens rubifolia $\mathrm{HBK}$; B) Bidens gardneri Bak;
C) Bidens pilosa L.;
C) B. pilosa (=subalternans) 


\section{CONCLUSÕES}

- O crisomelídeo Phaedon pertinax Stal, 1860 é uma espécie promissora para o controle biológico da planta daninha Bidens pilosa $\mathrm{L}$..

- As espécies de Bidens e Coreopsis sp. são plantas nutricionalmente adequadas para a alimentação do inseto.

- Há algum risco de introdução de $P$. pertinax como agente de controle biológico, em locais onde Coreopsis sp. for considerada planta ornamental.

- Cosmos sulphureus, apesar de ser uma planta atrativa a $P$. pertinax, apresenta efeito de antibiose.

- Os adultos são mais seletivos que as larvas de 1음 ínstar para os testes de antixenose. 
- P. pertinax é um inseto oligófago, restrito a poucas espécies da tribo Heliantheae, relacionadas a $B$. pilosa

- Quando as plantas não são adequadas para a alimentação da fêmea ocorre retenção de ovos.

- C. sulphureus e Coreopsis sp. mostram moderada atratividade para oviposição, quando em presença de B. pilosa.

- Bidens rubifolia é a planta mais preferida para postura e alimentação do adulto.

- Os danos mais severos à $B$. pilosa são provocados pelas larvas do inseto.

- P. pertinax, desenvolvendo-se em B. pilosa, apresenta a duração média de uma geração em 13,75 semanas, aumentando sua população 445,03 vezes a cada geração. 


\section{REFERÊ NCIAS BIBLIOGRÁFICAS}

ADAIR, R.J. \& SCOTT, J.K. Distribution, life history, host specificity and suitability of an undescribed Chrysolina species (Coleoptera: Chrysomelidae) for the biological control of Chrysanthemoides monilifera (Compositae). Bulletin of Entomological Research, London, 81: 235-242, 1991.

ARANHA, C.; BACCHI, O.; LEITÃO FILHO, H.F Plantas invasoras de culturas, São Paulo, HUCITEC, 1982. v.2, $597 \mathrm{p}$.

ARANHA, C.; LEITÃO FILHO, H.F.; YAHN, C.A. Sistemática de plantas invasoras, Campinas, Instituto Campineiro de Ensino Agrícola, 1988.174p.

BALLARD, D. Bidens pilosa complex (Asteraceae) in North and Central America. American Journal of Botany, New York, 73(10):1452-1465, 1986 . 
BARROSO, G.M.; PEIXOTO, A.L.; ICHASO; C.L.F.; COSTA, C.G.; GUIMARÃES, E.F.; LIMA, H.C. de. Sistemática de angiospermas do Brasil. Viçosa, Imprensa Universitária da Universidade Federal de Viçosa, 1986. v.3, p. 257-311.

BECHYNÉ, J. Notes sur le Chrysomélides de l'Amérique du Sud, I. (Col.). Revista de Entomologia, Rio de Janeiro, 21: $115-156,1950$.

BERTELs, A. Pragas de solanáceas cultivadas. Agros, Pelotas, 6(4): $154-160,1953$.

BERTELS, A. Insetos-hóspedes de solanáceas. Iheringia, Porto Alegre, 25: 1-11, 1962 .

BLANCO, H.G. Catálogo das espécies de mato infestantes de áreas cultivadas no Brasil - Família do picão-preto (Compositae). O Biológico, São Paulo, 42: 62-97, 1976.

BLANCO, H.G.; OliveirA, D.A.; PUPO, E.I.H. Período de competição de uma comunidade natural de mato em uma cultura de café, em formação. O Biológico, São Paulo, 48: 9-20, 1982 . 
BLANCO, H.G. \& SANTOS, C.A.L. Plantas daninhas predominantes em áreas cultivadas com milho no Estado de São Paulo. O Biológico, São Paulo, 54(1/6): 1-7, 1988.

CERNA, L. \& VALDÉZ, V. Influencia de las poblaciones de las malezas Sorghum halepense (L.) Pers. Y Bidens pilosa L. sobre el rendimiento de frijol (Phaseolus vulgaris L.) 'Pirata 2'. Turrialba, Costa Rica, 37(4): 303-309, 1987.

CHARUDATTAN, R. Controle biológico de plantas daninhas através de fitopatógenos. In: CURSO INTERNACIONAL SOBRE CONTROLE BIOLÓGICO DE PLANTAS DANINHAS, 1993, Jaboticabal. Jaboticabal, UNESPFCAVJ, 1993. p.1-34.

COX, M.L. The larvae of the British Phaedon (Coleoptera: Chrysomelidae, Chrysomelinae). Entomologist's Gazette, Faringdon, 42: 267-280, 1991 .

DYAR, H.G. The number of molts of lepidopterous larvae. Psyche, Massachussets, 5: 420-2, 1890 . 
FORNO, I.W.; KASSUlKE, R.C; HARLEY, K.L.S. Host specificity and aspects of the biology o Calligrapha patherina (Col.: Chrysomelidae), a biological control agent of Sida acuta [Malvaceae] and S. rhombifolia in Australia. Entomophaga, Paris, 37(3): 409-417, 1992.

GOEDEN, R.D. Critique and revision of Harris' scoring system for selection agents in biological control of weeds. Protection Ecology, Amsterdam, 5: 287-301, 1983.

HARRIS, P. The selection of effective agents for the biological control of weeds. Canadian Entomologist, Ottawa, 105: $1495-1503,1973$.

HARRIS, P. \& ZWOLFER, H. Screening of phytophagous insects for biological control of weeds. Canadian Entomologist, Ottawa, 100: 295-303, 1968 .

HUBER, J.T. \& VAYSSIERES, J.F. Life cycle and host specificity of the heliotrope weevil, Pachycerus cordiger ( $=$ madidus auct.) (Col.: Curculionidae). Entomophaga, Paris, 35(3): 475-484, 1990 .

HUFFAKER, C.B. Fundamentals of biological control of weeds. Hilgardia, Berkeley, 27(3): 101-157, 1957. 
HUFFAKER, C.B. Biological control of weeds with insects. Annual Review of Entomology, Palo Alto, 4: 251-276, 1959.

INTERNATIONAL INSTITUTE OF BIOLOGICAL CONTROL. Screening organisms for biological control of weeds. England, Farnham Royal, C.A.B. International, 1986.6p.

JULIEN, M.H.; KERR, J.D.; CHAN, R.R. Biological control of weeds: an evaluation. Protection Ecology, Amsterdam, 7: 325,1984 .

KISSMANN, K. \& GROTH, D. Plantas infestantes e nocivas. 2. dicotiledôneas. São Paulo, BASF Brasileira S.A., 1992. $798 \mathrm{p}$.

LIMA, A.M. da C. Terceiro catálogo dos insetos que vivem nas plantas do Brasil. Rio de Janeiro, Ministério da Agricultura, Escola Nacional de Agronomia, 1936. 460 p.

LIMA, A.M. da C. Sôbre espécies sul-americanas de Phaedon (Col. Chrysomelidae). Dusenia, Curitiba, 4(5,6): 429-433, 1953.

LIMA, A.M. da C. Insetos do Brasil. 9 tomo: Coleópteros (3a parte). Rio de Janeiro, Escola Nacional de Agronomia, IBGE, 1955. 289 p. (Série Didática, 11). 
LORENZI, H. Plantas daninhas do Brasil: Terrestres, aquáticas, parasitas, tóxicas e medicinais. Nova Odessa, H. Lorenzi, 1982. 425 p.

MARINIS, G. Nota sobre a capacidade reprodutiva de Bidens pilosa L. Revista de Agricultura, Piracicaba, 48(2/3): 95$100,1973$.

MENDES, L.O.T. Relação dos insetos encontrados sobre plantas do Estado de São Paulo nos anos de 1936-1937. Revista de Agricultura, Piracicaba, 13(10-12): 482-490, $1938 \mathrm{a}$.

MENDES, L.O.T. Observações sobre alguns insetos coletados sobre algodoeiro durante os anos de 1936 e 1937. Jornal de Agronomia, Piracicaba, 1(2): 149-162, 1938 b.

MORÁN LEMIR, A.H. Biologia de Phaedon consimilis Stal (Coleoptera: Chrysomelidae) y efecto de su ataque a Flaveria bidentis (L.) O.K. (Compositae) en Tucumán y Santiago del Estero (Argentina). CIRPON, Revista de Investigación, San Miguel de Tucumán, 1(3): 103-115, 1983. 
MORÁN LEMIR, A.H. Entomofauna relacionada con Flaveria bidentis (L.) O.K. (Compositae) en las provincias de Tucumán y Santiago del Estero (Republica Argentina). CIRPON, Revista de Investigación, San Miguel de Tucumán, 3(1-2): 39-52, 1985 .

RIBEIRO, J.H.C. Sobre um inimigo do Bidens pilosus. Agronomia, Campo Grande, 12(2): 51-53, 1953.

SCHROEDER, D. \& GOEDEN, R.D. The search for arthropod natural enemies of introduced weeds for biological control in theory and practice. Biocontrol News and Information, Farnham House, 7(3):147-155, 1986.

SILVA, A.G.A.; GONÇALVES, C.R.; GALVÃO, D.M.; GONÇALVES, A. J.L.; GOMES, J.; SILVA, M.N.; SIMONI, L. Quarto catálogo dos insetos que vivem nas plantas do Brasil, seus parasitos e predadores. Rio de Janeiro, Ministério da Agricultura, DDIA, SDSV, Laboratório Central de Patologia Vegetal, 1968. 4 v.

SILVEIRA NETO, S.; NAKANO, O.; BARBIN, D.; VILLA NOVA, N.A. Manual de ecologia dos insetos. São Paulo, Ceres, 1976. 419p. 
STEVENS, JR., G.A. \& TANG, C.S. Inhibition of seedling growth of crop species by recirculating root exudates of Bidens pilosa L. Journal of Chemical Ecology, New York, 11(10): $1411-1425,1985$.

TAMASHIRO, J.Y. \& LEITÃO FILHO, H.F. Observações sobre o ciclo de vida de Bidens pilosa L. (Compositae Heliantheae). Hoehnea, São Paulo, 7: 27-40, 1978.

WAPSHERE, A.J. Host specificity of phytophagus organisms and the evolutionary centres of plant genera and subgenera. Entomophaga, Paris, 19:301-309, 1974a.

WAPSHERE, A.J. A strategy for evaluating the safety of organisms for biological weed control. Annals of Applied Biology, London, 77: 201-211, 1974b.

WAPSHERE, A.J. A protocol for programmes for biological control of weeds. Pest Articles and News Summaries (PANS), London, 21: 295-303, 1975.

WAPShERE, A.J.; DELFOSSE, E.S.; CUllen, J.M. Recent developments in biological control of weeds. Crop Protection, Guildford, 8(4): 227-250, 1989. 
WILsOn, F. The biological control of weeds. Annual Review of Entomology, Palo Alto, 9: 225-244, 1964.

ZWOLFER, H. \& HARRIS, P. Host specificity determination of insects for biological control of weeds. Annual Review of Entomology, Palo Alto, 16: 159-178, 1971. 
APÊNDICE 1. Revisão proposta por GOEDEN (1983) do sistema de pontuação (escores) de HARRIS (1973) para avaliar insetos fitófagos como candidatos ao controle biológico de plantas daninhas.

\section{AVALIAÇÃO INICIAL DA CAPACIDADE INATA DE DANO}

1.Dano direto em condições de campo

(A) minador de folhas 1

(B) sugador ou formador de galhas 2

(C) desfolhador ou sugador (injeção de toxinas) 4

(D) destruição do suporte vascular ou macânico de tecidos como endófago

(E) destruição substancial de sementes

- planta perene (de longa vida) 1

- planta não dependente de reprodução por sementes (de curta vida) 2

- planta anual ou bi-anual (de reprodução por

\section{Danos indiretos}
(A) nenhum
(B) Iimitados
(C) planta hospedeira torna-se suscetivel ao ataque de insetos ou fitopatógenos secundários
(D) Vetor de fitopatógeno virulento

\section{Fenologia do ataque}

(A) período de ataque limitado não aumentando a suscetibilidade da planta a seca, geada ou competição com outras plantas

(B) período de ataque limitado por insetos que atacam sementes não cobrindo inteiramente o período reprodutivo da planta daninha

(C) período de ataque limitado, porém aumentando a suscetibilidade da planta hospedeira a seca, geada ou competição com outras plantas

(D) período de ataque prolongado cobrindo inteiramente a estação de desenvolvimento ou período reprodutivo da planta daninha (por insetos que atacam sementes) 
4.Número de gerações

(A) espécies univoltinas obrigatórias 0

(B) duas ou três gerações anuais 2

(C) quatro ou mais gerações por ano 3

5.Número de progênie por fềmea por geração
(A) $<500$
0
(B) $500-1000$
2
(C) $>1000$

\section{Fatores extrínsecos de mortalidade}

(A) controle natural largamente afetado por inimigos naturais não especificos ou fatores ecológicos abióticos

(B) sujeito a extensiva mortalidade por competidores na planta hospedeira, combinados com a ocorrência comum

(C) sujeito a extensiva mortalidade de inimigos especializados, incluindo doenças, e relativamente imune a inimigos não especificos

7. Comportamento alimentar
(A) Solitário
0
(B) Gregário.

8. Distribuição

(Extensão da população da planta invasora)
(A) Somente local
0
(B) Cobre um quarto
2
(B) Cobre três quartos
4
(C) Cobre totalmente
6 
APÊNDICE 1. (continuação)

\section{ADEQUAÇÃO DE USO COMO AGENTE DE CONTROLE BIOLÓGICO}

1.Fonte da planta hospedeira do inseto
(A) obtido de gêneros diferentes da planta hospedeira alvo (oligófago)
(B) obtido dentro do mesmo gênero, porém não da mesma espécie da planta alvo
(C) obtido da planta daninha alvo como planta hospedeira

2. Facilidade de criação

(A) criação impossivel, muito trabalho para coleta de espécimes no campo

(B) criação difícil sobre a planta daninha alvo ou somente possivel em restrito estágio de desenvolvimento das plantas hospedeiras.

(C) criação fácil en dieta artificial ou facilmente criado sobre a planta hospedeira, incluindo a planta daninha alvo

\section{Segurança potencial}

(A) Citado atacando plantas úteis

(B) Não conhecido como praga, porém apresentando espécies congêneres como pragas

(C) Não citado como praga, sem espécies do mesmo gênero como pragas

\section{Especificidade hospedeira}

(A) POLIFAGO

Alimenta-se facilmente sobre plantas em testes de fome sob condições de laboratório - 6

(B) MONÓFAGO OU OIIGÓFAGO

Não se alimenta em testes de fome de plantas sob condições de laboratório 


\section{EFICÁCIA POTENCIAL NA ÁREA DE INTRODUÇÃO}

1. Evidência de efícácia como agente de controle biológico
(A) Fracassado como agente de controle biológico em uma ou mais regiões do mundo
(B) Primeiro uso como agente de controle biológico
(C) Controla a planta hospedeira na região nativa ou uma região de introdução
(D) Bem sucedido em duas ou mais regiões do mundo

\section{Similaridade eco-climática}
(A) Eco-clima da área de introdução consideravelmente mais severo do que na região de distribuição nativa do agente $\quad-10$
(B) Eco-clima da região de distribuição nativa parcialmente similar ao da área de introdução
(C) Eco-clima da área de introdução similar ao da região de distribuição nativa do agente

\section{História da colonização do agente}

(A) Estabelecimento acidental prematuro sobre a planta daninha alvo na área de introdução determinado por levantamentos faunisticos de pré-introdução

(B) Ausência sobre a planta daninha na área de introdução 